
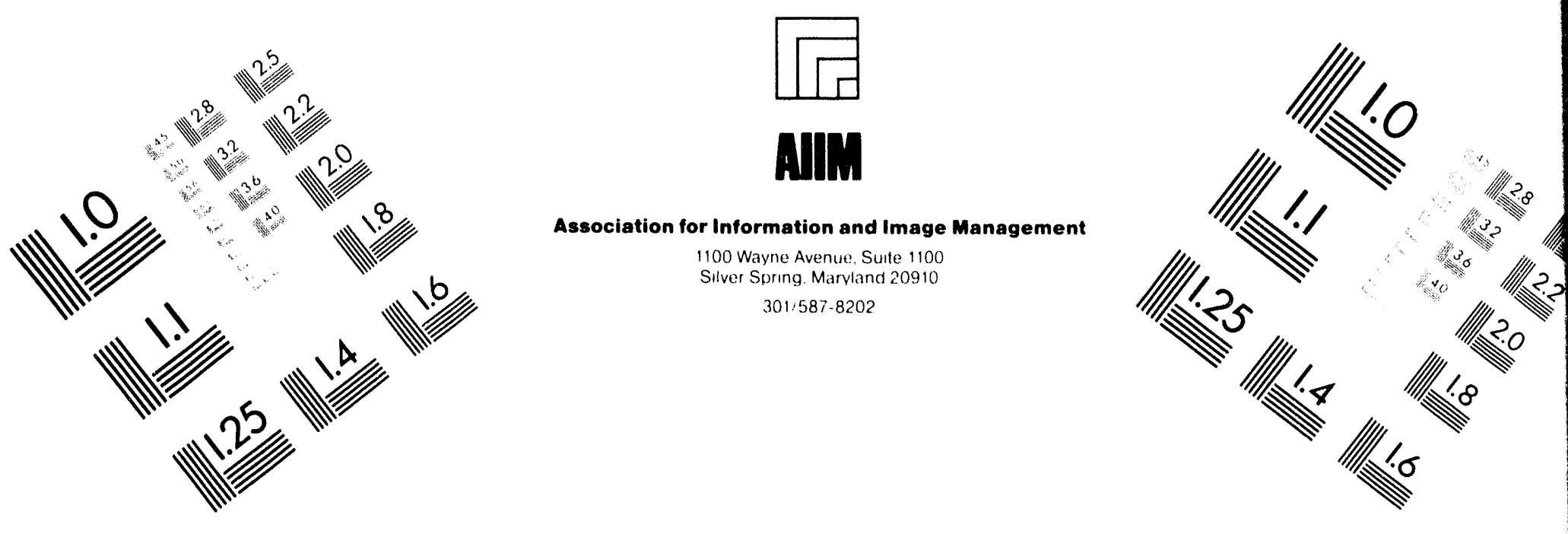

\title{
Centimeter
}

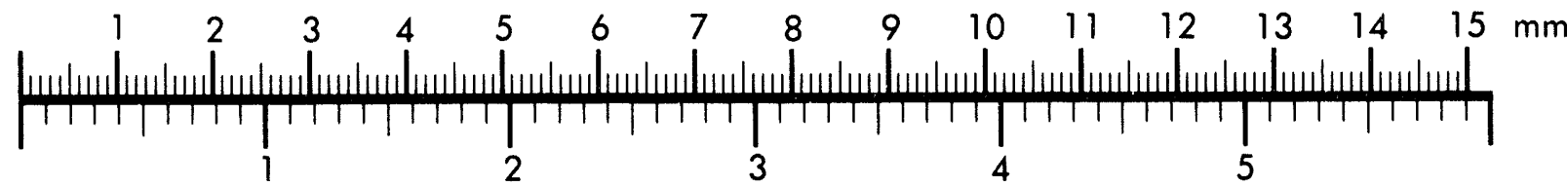

Inches
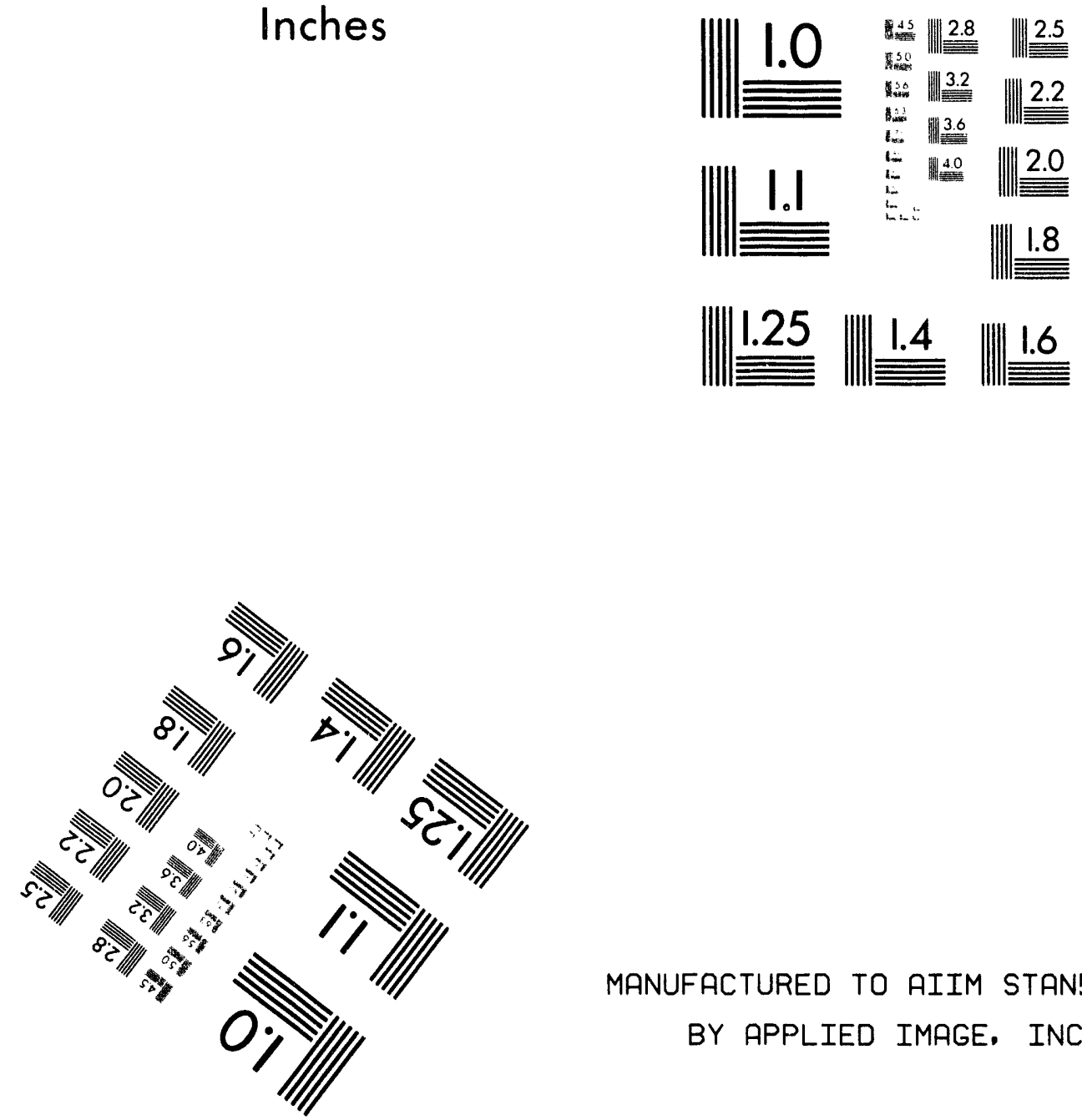

MANUFACTURED TO AIIM STANDARDS

BY APPLIED IMAGE. INC.

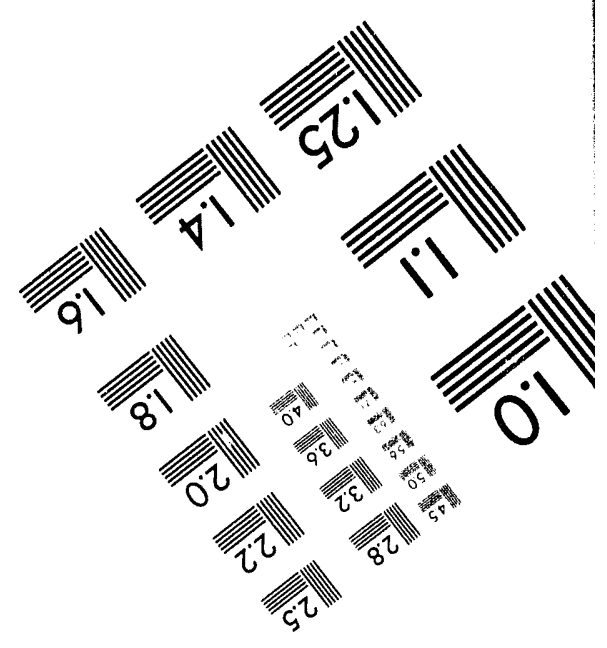



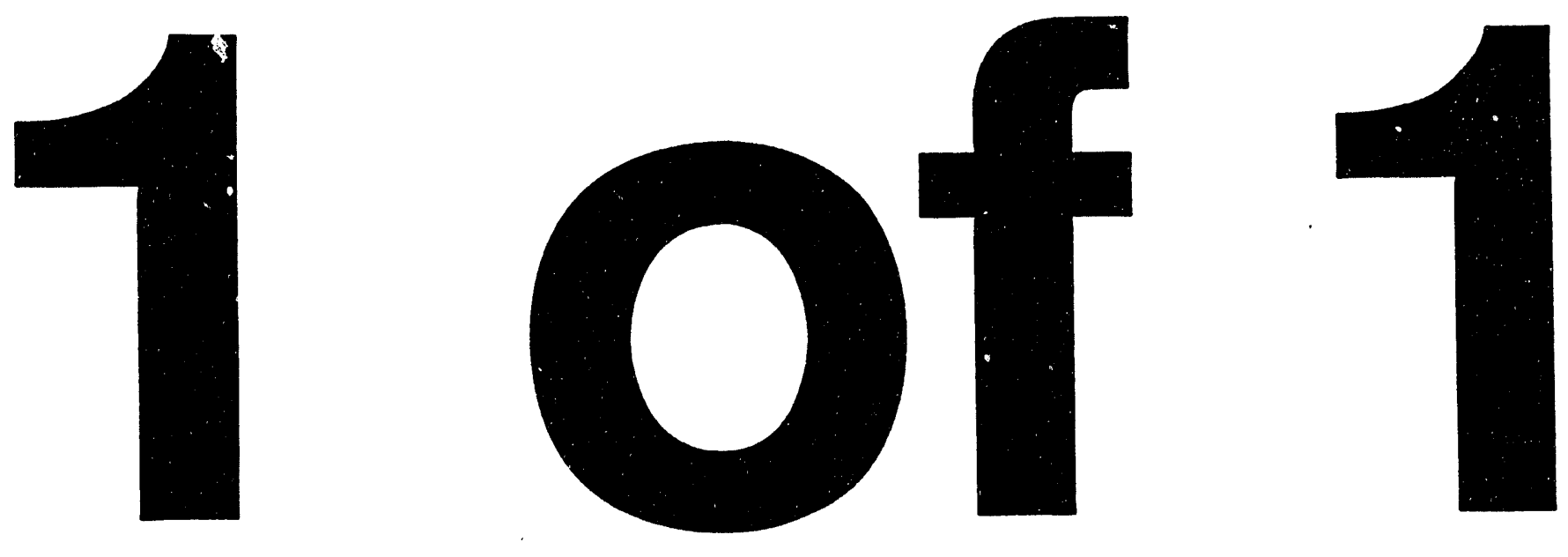


\title{
Characterization of the Corrosion Behavior of the Carbon Steel Liner in Hanford Site Single-Shell Tanks
}

\author{
R. P. Anantatmula \\ E. B. Schwenk \\ Westinghouse Hanford Co \\ M. J. Danielson \\ Pacific Northwest Laboratory \\ Date Published \\ June 1994
}

Prepared for the U.S. Department of Energy Office of Environmental Restoration and Waste Management

\footnotetext{
(W) Westinghouse

Hanford Company Richland, Washington 99352

Hanford Operations and Engineering Contractor for the

U.S. Department of Energy under Contract DE-AC06-87RL 10930
} 
This page intentionally left blank. 
Document Title: Characterization of the Corrosion Behavior of the Carbon Steel Liner in Hanford Site Single-Shell Tanks

P.P. Anantatmule

R. P. Anantatmula, Fellow Engineer

Corrosion Engineering

Prepared by:

Prepared by:

Approved by:

Approved by:

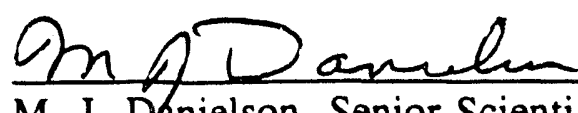

M. J. Danielson, Senior Scientist

Materials Applications

Pacific Northwest Laboratory

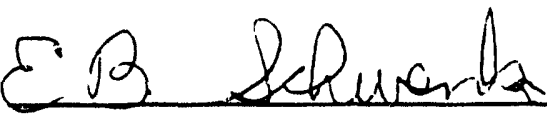

E. B. Schwenk, Principal Engineer

$\overrightarrow{1 C} \mathrm{w} \cos$

P. C. Ohl, Manageı

Corrosion Engineering
System Structural Integrity Assessments

$6 \longdiv { 2 2 / 9 4 }$

Date

$\frac{6 / 2+/ 94}{\text { Date }}$

$\frac{6 / 21 / 94}{\text { Date }}$

$t \mid 21 / \sqrt{24}$

Date

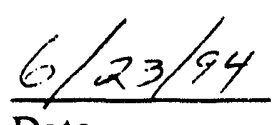

Date

D. B. Engelman, Manager

Tank Stabilization and Engineering Support 


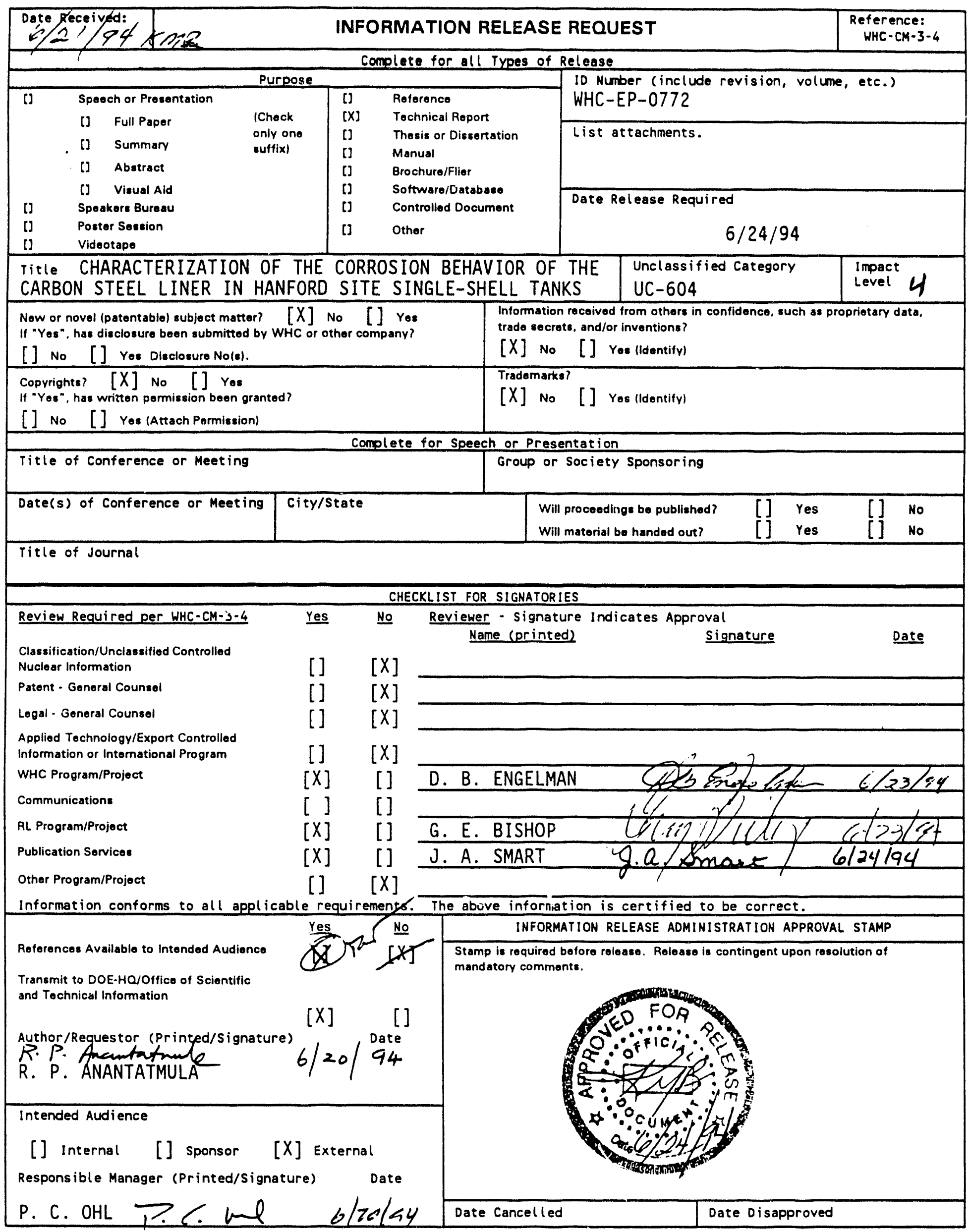




\section{CHARACTERIZATION OF THE CORROSION BEHAVIOR OF THE CARBON STEEL LINER IN HANFORD SITE SINGLE-SHELL TANKS}

\section{EXECUTIVE SUMMARY}

Six safety initiatives have been identified for accelerating the resolution of waste tank safety issues and closure of unreviewed safety questions. These initiatives are key drivers for building and maintaining the momentum to correct tank farm problems. Safety Initiative 5 is to reduce safety and environmental risk from tank leaks. Item d of Safety Initiative 5 is to complete corrosion studies of single-shell tanks to determine failure mechanisms and corrosion control options to minimize further degradation by June 1994.

This report has been prepared to fulfill Safety Initiative 5, Item d. The corrosion mechanisms that apply to Hanford Site single-shell tanks are stress corrosion cracking, pitting/crevice corrosion, uniform corrosion, hydrogen embrittlement, and microbiologically influenced corrosion. Accurate determination of single-shell tank failure mechanisms involves laboratory experiments using synthetic wastes to simulate the wastes in the singleshell tanks coupled with the destructive and non-destructive examination of single-shell tanks to compare the laboratory data with the actual corrosion of the tanks. The corrosion data relevant to the single-shell tanks dates back three decades, when results were obtained from in-situ corrosion coupons in a few single-shell tanks. Since that time there have been intertank transfers, evaporation, and chemical alterations of the waste. These activities have changed the character and the present composition of the waste is not well characterized. 
All conclusions and recommendations are made in the absence of relevant laboratory experimental data and tank inspection data. The report attempts to identify the failure mechanisms by a literature survey of carbon steel data in environments similar to the singleshell tank wastes, and by a review of the work performed at the Savannah River Site where similar wastes are stored in similar carbon steel tanks. This approach indicated that in highnitrate wastes containing insufficient quantities of hydroxide and nitrite, carbon steel will fail by stress corrosion cracking especially in weld heat affected zones. This observation was supported by examining data obtained from Savannah River Site tank 16, which had not been given a stress-relief anneal after fabrication (which is the case with all Hanford single-shell tanks). In addition, carbon steels are expected to corrode by pitting if the hydroxide concentration is reduced below a pH value of 10 . This is evidenced by laboratory data and the examination of failed cooling coils in waste tanks at the Savannah River Site. Based on these surveys, and in the absence of data specific to Hanford single-shell tanks, it may be concluded that the single-shell tanks identified as leakers failed primarily by stress corrosion cracking due to the presence of high nitrate/low hydroxide wastes and residual stresses. In addition, some failures may be attributed to pitting under crevices in low hydroxide locations.

Additional support for these conclusions is obtained from a review of record of waste types stored in the single-shell tanks versus the leak status of these tanks. There appears to be a direct correlation between the high nitrate/low hydroxide concentration of the stored waste types and the leak status for the majority of leaking tanks. 
After an extensive literature review, it has been determined that uniform corrosion, $Y$ hydrogen embrittlement and microbiologically influenced corrosion are not relevant mechanisms for single-shell tank failure.

Based on the above analysis, the ranking of failure mechanisms for Hanford single-shell tanks in order of decreasing importance is:

- Stress corrosion cracking

- $\quad$ Pitting/crevice corrosion

- Uniform corrosion

- Hydrogen embrittlement

- Microbiologically influenced corrosion.

Other failure mechanisms such as radiation damage, liquid metal embrittlement, galvanic corrosion, intergranular corrosion, creep, erosion corrosion, caustic cracking, selective leaching, wear, and thermal embrittlement were not considered.

\section{RECOMMENDATIONS}

To control or mitigate corrosion, the methods usually employed are material selection, application of coatings, environment modification, and cathodic protection. It is too late for all these options for Hanford single-shell tanks except for environment modification (chemistry adjustment). 
The following specific recommendations are made to control corrosion and to assist in the resolution of outstanding unreviewed safety questions. These recommendations are discussed in more detail in Section 5.0; they are specific to the tanks indicated. The tanks are listed in decreasing order of priority for the action under consideration.

1. Remove as much liquid as possible by expediting stabilization, then by forced evaporation (if possible) from tanks that are sound and are suspected of having waste that is much more aggressive than the tanks listed below. Options to reduce condensation should also be considered. (Tanks BY-109, BY-102, BX-106, C-102, C-105, C-103, and C-106.)

2. Add a corrosion inhibitor (e.g., sodium hydroxide) to tanks that are sound and will not be interim stabilized in the near future and are suspected of having liquids that do not meet tank waste specifications. (Tanks U-103, U-102, U-111, U-106, U-105, U107, U-108, U-109, S-102, S-111, S-106, S-109, S-108, S-110, S-112, S-103, S-101 and S-107.)

3. Install corrosion monitoring probes and/or coupons (stress corrosion cracking) in tanks that are sound but are suspected of having liquids that do not meet tank waste specifications. These tanks are on a lower priority for adding inhibitors because their wastes are not as aggressive as the tanks categorized for inhibitor addition. (Tanks SX-105, SX-106, SX-102, SX-101, SX-103, T-110 and T-104.) 
The following general recommendations to improve the ability to predict and control tank failure mechanisms are also made:

1. Characterize the waste in all single-shell tanks because the waste has stratified over the years, and the composition probably varies with the depth of the waste. Characterization can be carried out initially by core sampling one tank from each group of tanks containing same waste types. It should start with sound tanks that are not stabilized.

2. Perform failure analysis by inspecting the tank vapor space with remote video equipment. The capability should exist for high pressure washing of the wall deposits to verify whether stress corrosion cracking or pitting has penetrated the tank wall. Failure analysis should be done on a failed tank from the REDOX waste group or the tributyl phosphate group. In addition, perform non-destructive and metallographic analysis on a tank that will be emptied in the future.

3. Perform laboratory tests using synthetic wastes under simulated conditions to determine the rates of the most probable failure mechanisms. 
WHC-EP-0772

This page intentionally left blank. 


\section{CONTENTS}

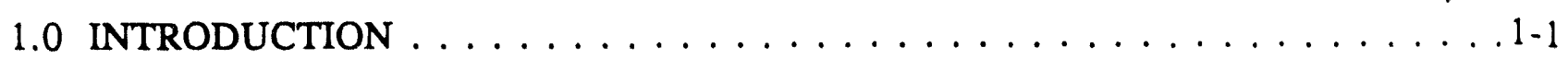

2.0 ASSESSMENT OF HANFORD SINGLE-SHELL TANK CORROSION

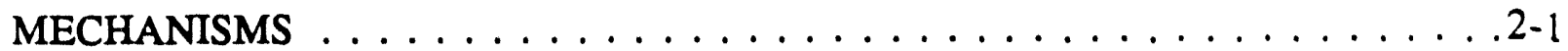

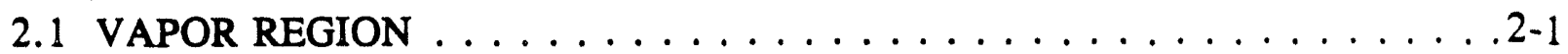

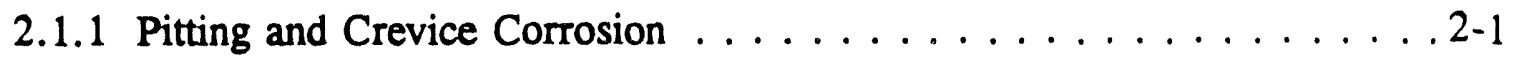

2.1.2 Stress Corrosion Cracking $\ldots \ldots \ldots \ldots \ldots \ldots \ldots \ldots \ldots \ldots \ldots \ldots .2-2$

2.1.3 Hydrogen Embrittlement $\ldots \ldots \ldots \ldots \ldots \ldots \ldots \ldots \ldots \ldots .2-2$

2.1.4 Uniform Corrosion . . . . . . . . . . . . . . . . . . . . 2-2

2.1.5 Microbiologically Influenced Corrosion $\ldots \ldots \ldots \ldots \ldots \ldots . . \ldots 2-3$

$2.2 \mathrm{VAPOR} / L I Q U I D$ INTERFACE AND VAPOR/LIQUID/SOLID

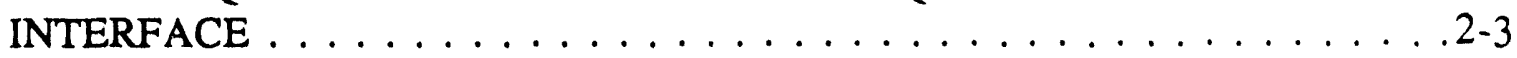

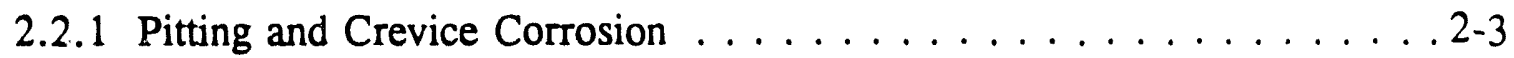

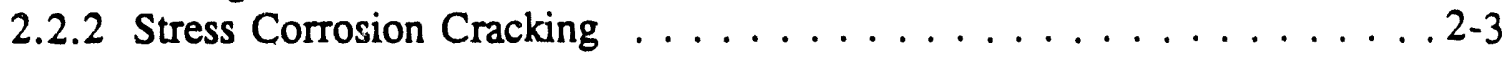

2.2.3 Hydrogen Embrittlement . . . . . . . . . . . . . . . .2-4

2.2.4 Uniform Corrosion . . . . . . . . . . . . . . . . . . . .2.4

2.2.5 Microbiologically Influenced Corrosion . . . . . . . . . . . 2-4

2.3 LIQUID REGION AND LIQUID/SOLID INTERFACE $\ldots \ldots \ldots \ldots . . .24$

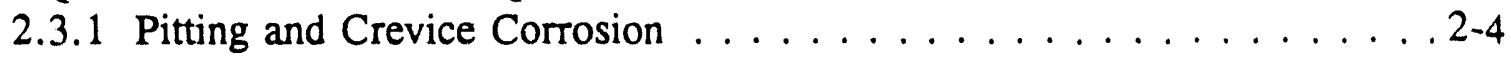

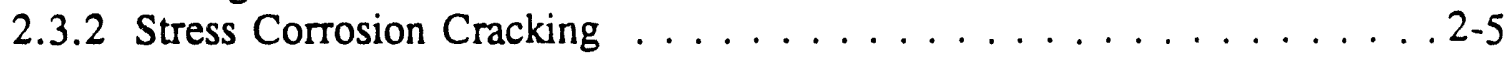

2.3.3 Hydrogen Embrittlement . . . . . . . . . . . . . . . 2-5

2.3.4 Uniform Corrosion . . . . . . . . . . . . . . . . . . 2-6

2.3.5 Microbiologically Influenced Corrosion . . . . . . . . . 2-6

3.0 CORRELATION STUDIES (WASTE TYPE VERSUS ASSUMED LEAKER

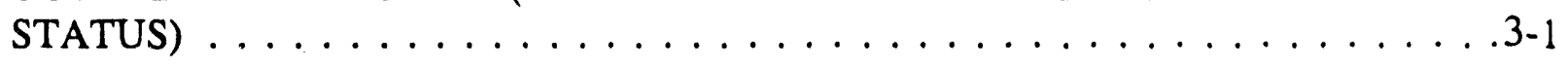

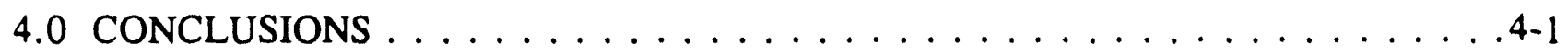

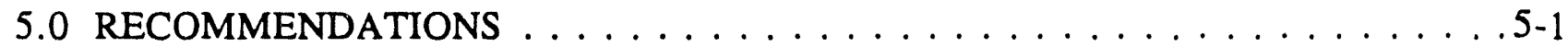

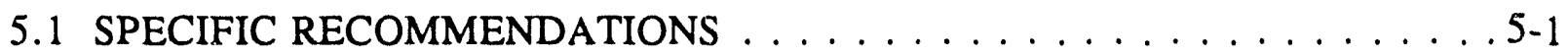

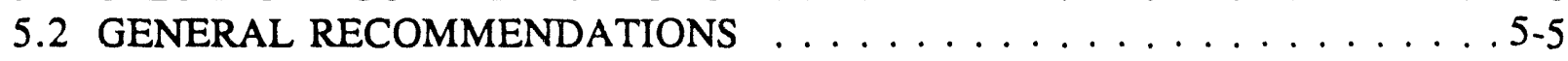

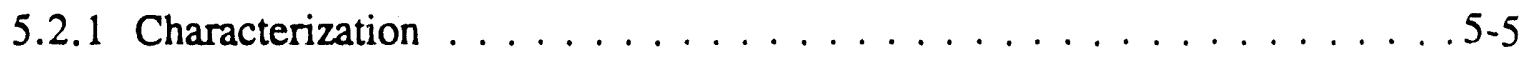

5.2 .2 Failure Analysis . . . . . . . . . . . . . . .5-5

5.2 .3 Laboratory Testing $\ldots \ldots \ldots \ldots \ldots \ldots \ldots \ldots \ldots$

6.0 REFERENCES . . . . . . . . . . . . . . . . . . . . 6-1 


\section{CONTENTS (continued)}

\section{APPENDIX}

A REVIEW OF CARBON STEEL CORROSION LITERATURE . . . . . . . . . . A-1

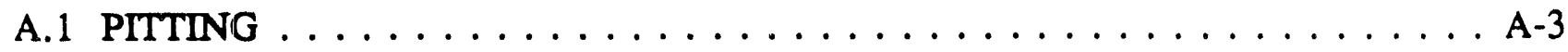

A.1.1 Pitting Experience Outside the Nuclear Industry . . . . . . . . . . A-3

A.1.2 Pitting Corrosion Data on Carbon Steel Nuclear Waste Storage Tanks . . . A-4

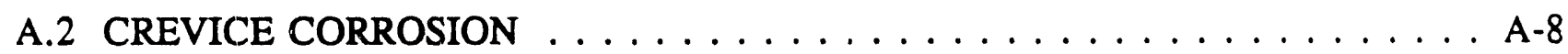

A.3 STRESS CORROSION CRACKING $($ SCC $) \ldots \ldots \ldots \ldots \ldots \ldots \ldots$

A.4 HYDROGEN EMBRITTLEMENT . . . . . . . . . . . . . . . . . . . A-12

A.4.1 Three Forms of Hydrogen Damage in Steels . . . . . . . . . . . . . . A-13

A.4.1.1 Loss of Tensile Ductility . . . . . . . . . . . . . . A A-13

A.4.1.2 Formation of Blisters . . . . . . . . . . . . . . . A-13

A.4.1.3 Hydrogen Stress Cracking . . . . . . . . . . . . . A A-15

A.4.2 Hydrogen Generation Processes . . . . . . . . . . . . . . . . A-17

A.4.3 Hydrogen Embrittlement Characteristics of Steels . . . . . . . . . . . A A-20

A.4.4 Hydrogen Embrittlement Mechanisms and Failure Modes Applied

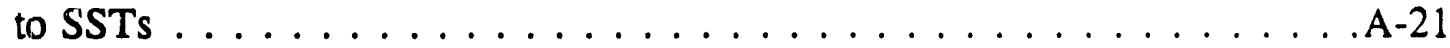

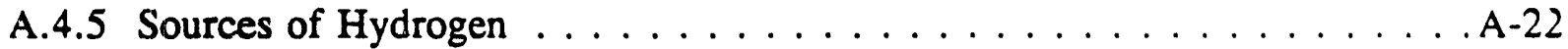

A.4.6 Detailed Discussion of Factors that Could Affect Hydrogen Damage

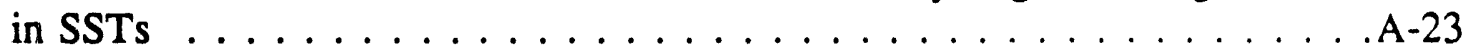

A.4.6.1 Hydrogen Embrittlement (Vapor Region) . . . . . . . . . . A-23

A.4.6.2 Hydrogen Embrittlement (Vapor-Liquid and Vapor-Liquid-Solid Interface) . . . . . . . . . . . . . . . . A-24

A.4.6.3 Hydrogen Embrittlement (Liquid Region and Liquid-Solid) . . . A-25

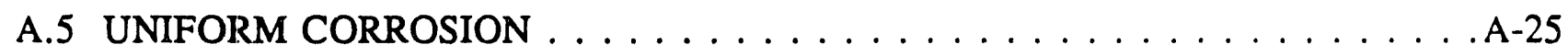

A.6 MICROBIOLOGICALLY INFLUENCED CORROSION (MIC) . . . . . . . . A A-26 


\section{LIST OF FIGURES}

A-1 The Variation of Elongation with Hydrogen Content for a Normalized Mild Steel Tested at a Slow Strain-Rate at Room Temperature . . . . . . . . . . . . A-14

A-2 Hydrogen-induced Slow Crack Growth as a Function of Applied Stress Intensity Factor in a Martensitic (4130) Steel Tempered to Various Strength Levels

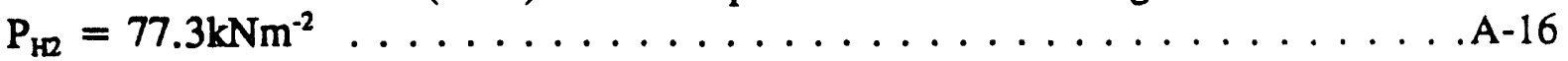

A-3 Typical Forms of Crack Growth Rate (da/dt) Versus Stress-Intensity Factor Curves for (a) Hydrogen Stress Cracking and (b) Stress Corrosion Cracking . . . A-18

\section{LIST OF TABLES}

1-1 Types of Steel Used in the Construction of Single-Shell Tanks . . . . . . . . . 1-2

3-1 Relationship Between Tank Failure and Waste Composition for the Single-Shell Tanks . . . . . . . . . . . . . . . . . . . 3-2

5-1 Waste Grouping Versus Leak Siatus for the single-Shell Tanks . . . . . . . . . 5-2

5-2 Corrosivity Factors for the Wasic Types Used in Assigning Priorities . . . . . . 5-4

A-1 Corrosion Data for Carbon Steel in Various Tanks and from Laboratory Tests . . . . . . . . . . . . . . . . . . . . . A-5

A-2 Calculated Nitrite/Nitrate Ratios for Pitting Inhibition for $\mathrm{pH} \sim 10 \ldots \ldots$ A-7

A-3 Target Composition of Tank 8D-2, Third-Stage Wash Simulant $\ldots \ldots \ldots \ldots$ A-8

A-4 Recommended Anion Limits (Ondrejcin et al. 1979 and Kirch 1984) for Safe Storage of Liquid High-Level Wastes . . . . . . . . . . . . . A-10

A-5 Compositions for Low Temperature SCC $\ldots \ldots \ldots \ldots \ldots \ldots \ldots$ A 12 
WHC-EP-0772

This page intentionally left blank. 


\section{LIST OF TERMS}

$1 \mathrm{C}$

2C

224

5-6

CCPLX

CF

CW

D

DIA

DOE

DSSF

DST

EB

EB-ITS

HAR

HE

HSC

HSSC

IC-F

IX

$\mathrm{K}$

$\mathrm{K}_{\mathrm{ISCC}}$

$\mathrm{ksi}$

$\mathrm{K}_{\mathrm{th}}$

MIC

MIX

mpy

NCPLX

OWW

psi

REDOX

SCC

SI-5

SI-5d

SS

SST

TBP

UST

USQ first cycle decontamination waste

second cycle decontamination waste

lanthanum fluoride decontamination waste

B Plant Waste

complex concentrate

corrosivity factor

cladding waste

steady-state diffusivity

diatomaceous earth

U.S. Department of Energy

double-shell slurry feed

double-shell tank

evaporator bottoms

evaporator bottoms in-tank solidification

hydrogen absorption reaction

hydrogen embrittlement

hydrogen stress cracking

hydrogen assisted stress cracking

first cycle ferrocyanide scavenged waste

ion exchange waste

stress intensity factor

threshold stress intensity factor

kilopounds per square inch

threshold stress intensity

microbiologically influenced corrosion

mixture of several miscellaneous wastes

mils per year

noncomplexed waste

organic solvent wash waste from PUREX

pounds per square inch

reduction oxidation waste

stress corrosion cracking

safety-initiative 5

safety-initiative 5 , item d

strontium sludge

single-shell tank

tributyl phosphate

underground storage tank

unreviewed safety question 
This page intentionally left blank. 


\section{CHARACTERIZATION OF THE CORROSION BEHAVIOR OF THE CARBON STEEL LINER IN HANFORD SITE SINGLE-SHELL TANKS}

\subsection{INTRODUCTION}

Carbon steel underground storage tanks (USTs) have seen used to store and process liquid high-level radioactive wastes generated from 50 years of weapons materials production at the U.S. Department of Energy (DOE) Hanford Site. The Hanford Site occupies 570 square miles of sagebrush steppe in Southeastern Washington State, and it currently stores and manages an estimated 61 million gallons of radioactive waste in 177 USTs. The USTs contain radioactive sludges, salt cake, and supernatant liquids. The major chemical constituents are nitrate and nitrite salts, hydrated metal oxides, phosphate precipitates, transuranics, and isotopes of cesium, strontium, iodine and technetium. The environment within the tanks is highly radioactive (up to 1000 roentgen per hour) and chemically harsh.

There are two types of USTs at Hanford, single-shell tanks (SSTs) and double-shell tanks (DSTs). Single-shell tanks have a single shell of carbon steel housed in a concrete wall and dome. More than one type of carbon steel was used in their construction (see Table 1-1). The SSTs were not stress-relieved after welding and fabrication operations were completed. The SSTs currently store an estimated 35 million gallons of sludge and salt cake and 5 million gallons of pumpable liquids. All have exceeded their design life. Of the 149 SSTs, 67 are known or assumed to have leaked radioactive waste to the surrounding soil. To minimize the impact of actual and potential leaks, 106 SSTs have been interim stabilized by pumping supernatant and interstitial liquids to DSTs. The DSTs are second generation tanks with an inner and outer shell and a dome of carbon steel (American Society for Testing and Materials [ASTM] A515, A516, A537) and an outer concrete wall and dome. Unlike the SSTs, the DSTs were stress-relieved prior to receiving waste, and their waste chemistries are controlled according to tank waste specifications. None of the DSTs has leaked.

In 1987, the Hanford mission changed from weapons materials production to environmental cleanup. The need for developing new waste retrieval and disposal technologies and constructing processing facilities to dispose of the nuclear wastes was recognized. While these technologies are being developed and processing facilities are being constructed, the wastes must be managed in a safe and environmentally responsible manner. 
Table 1-1. Types of Steel Used in the Construction of

Single-Shell Tanks.

\begin{tabular}{|c|c|c|c|c|}
\hline Type & Class: & Grade. & $\begin{array}{l}\text { Number } \\
\text { of Tanks }\end{array}$ & $\begin{array}{l}\text { Tank } \\
\text { Farms }\end{array}$ \\
\hline Structural & A7-39 & -- & 76 & $\begin{array}{c}\mathrm{B}, \mathrm{BX}, \mathrm{C}, \\
\mathrm{T}, \mathrm{U}\end{array}$ \\
\hline Plate & $\begin{array}{l}\mathrm{A} 283-46 \mathrm{~T} \\
49 \mathrm{~T}, 52 \mathrm{~T}\end{array}$ & B, C & 39 & $\begin{array}{l}\text { A, S, SX, } \\
\text { TY }\end{array}$ \\
\hline Flange & A285-46 & A, B, C & 30 & BY, TX \\
\hline Boiler & A201-61T & -- & 4 & $\mathrm{AX}$ \\
\hline
\end{tabular}

A tank waste remediation program has been established to manage the safe storage and eventual disposal of the radioactive wastes stored in these tanks. A number of significant safety issues associated with the wastes have been identified. These issues include the following: the periodic release of flammable gases, potentially unstable organic and ferrocyanide compounds, release of potentially toxic vapors, nuclear criticality concerns, and excessive heat generation. Some tanks have been identified as Watch List tanks requiring special controls as part of the Safety Measures Law (Public Law 101-510, Section 3137). Four safety issues involve unreviewed safety questions (USQs) requiring additional environmental and safety documentation in order to complete safety upgrades and sampling activities.

Six safety initiatives have been identified for accelerating the resolution of waste tank safety issues and closure of USQs. These initiatives are key drivers for building and maintaining the momentum to correct tank farm problems. Safety Initiative 5 (SI-5) is to reduce the safety and environmental risk from tank leaks. Item d of SI-5 (SI-5d) is to complete corrosion studies of single-shell tanks to determine failure mechanisms and corrosion control options to minimize further degradation by June 1994.

This report has been prepared to fulfill SI-5d. It includes an assessment of the SSTs corrosion mechanisms supported by the carbon steel corrosion literature review (see Appendix A). The report also includes an assessment based on the corrosion potential of the actual waste types versus the leak status of these tanks. Finally, the report concludes with a discussion of the corrosion mechanisms that are most likely responsible for tank degradation, recommendations for additional tests, examinations to verify the conclusions, and possible options to minimize further corrosion. 


\subsection{ASSESSMENT OF HANFORD SINGLE-SHELL TANK CORROSION MECHANISMS}

The carbun steel corrosion literature is extensively reviewed in Appendix A. The review focuses on the failure mechanisms of carbon steel relevant to the nuclear waste environment. Each waste tank region or interface (vapor, vapor/liquid, and liquid and/or liquid/solid) was considered from the standpoint of the unique environment it created. The principal failure mechanisms were examined and evaluated in each of these environments (pitting and crevice corrosion, stress corrosion cracking [SCC], hydrogen embrittlement [HE], uniform corrosion, and microbiologically influenced corrosion [MIC]). Radiation damage, liquid metal embrittlement, galvanic corrosion, intergranular corrosion, erosion corrosion, caustic cracking, selective leaching, creep, wear, and thermal embrittlement were not considered. Section 2.0 summarizes the conclusions in Appendix A.

\subsection{VAPOR REGION}

\subsubsection{Pitting and Crevice Corrosion}

The chemical components present in the condensed vapor phase should be somewhat similar to those present in the liquid phase. Droplets of the liquid phase are carried upwards when gas bubbles from boiling or a chemical process break through the meniscus and coat the vapor phase surfaces. Water vapor condensation dilutes and washes dissolved solids back into the liquid phase. The resulting wetted surfaces, equilibrated with air and the pHcontrolling effects of carbon dioxide should represent a dilute (low dissolved solids) chemistry whose $\mathrm{pH}$ is controlled by the carbonate/bicarbonate buffer (i.e., a pH $\leq 10$ ). The corrosion literature indicates that carbon steels are vulnerable to pitting under these conditions.

The waste repository literature demonstrates that pitting is a major problem in the vapor phase. Pitting rates of 2-37 mils per year (mpy) have been observed in tests indicating that penetration could occur through the 0.25 -inch thick steel plate of the SSTs within seven years. A plausible scenario (Leakage Mechanism \#1) for tank leakage is as follows:

1. A tank is partly filled with liquid.

2. Pits or cracks penetrate the tank wall in the vapor phase.

3. A later addition of more waste raises the liquid level.

4. A leak is possible until the waste returns to the original level.

Several authors have observed that the vapor phase pitting rate rapidly decreases with time, but the observation period of this assessment is usually six months or less. Consequently, short-term pitting data may result in an overestimate of the pitting rate and an underestimate of time for wall penetration. 
The literature does not show any waste-related crevice corrosion data for the vapor phase. Because of the similarity of propagation mechanisms for pitting and crevice corrosion, crevice corrosion may also be a problem. Potential sites for crevices in single-shell tanks (SSTs) are at chinks of attached salt crusts (formed from earlier fillings or by wicking and evaporation), in regions adjacent to the bituminous coatings originally between the concrete and steel shell (which later melted and run down the inside wall), and at the upper wall/ceiling junction.

\subsubsection{Stress Corrosion Cracking}

No SCC has been reported in the vapor phase. Based on the SCC propensity of pipeline steels in elevated temperature carbonate/bicarbonate solutions $(\mathrm{pH} \leq 10)$, there is a strong potential for SCC in the vapor phase when the temperature is $\geq 60^{\circ} \mathrm{C}$. Leakage would take place when the tank was filled to a level higher than existing cracks (Leakage Mechanism \#1).

\subsubsection{Hydrogen Embrittlement (Vapor Region)}

No hydrogen damage degradation mechanisms are expected in the vapor phase regions of the SST liners. This conclusion is based on the following assumptions and known conditions: relatively constant loadings on the liners, the lack of an electrochemical method to generate hydrogen at the metal interface, low hydrogen partial pressure, the presence of gaseous oxygen, no detectable hydrogen sulfide $\left(\mathrm{H}_{2} \mathrm{~S}\right)$, relatively low vapor space temperatures, exposure time approaching 50 years, and the desirable lows strength properties of carbon steel liners.

The term, relatively constant loadings, assumes the portion of the liner exposed to the vapor phase is backed up by concrete that has not suffered any change in shape or size. For example, it is assumed that a significant corrosion product buildup between the liner and the concrete, or a loss of concrete, has not occurred. A detailed discussion of the various conditions or states relative to the vapor phase is in Appendix A.

\subsubsection{Uniform Corrosion}

The corrosion literature indicates uniform corrosion is less important than pitting and can probably be ignored as a failure mechanism. 


\subsubsection{Microbiologically Influenced Corrosion}

There was no literature to evaluate MIC in a nuclear waste environment. Since condensation continuously washes the inside tank walls with high purity water, the nutrient level probably remains low. It is thought that microorganism growth rates are inhibited; consequently MIC has little or no role.

\subsection{VAPOR/LIQUID INTERFACE AND VAPOR/LIQUID/SOLID INTERFACE}

\subsubsection{Pitting and Crevice Corrosion}

It has been experimentally confirmed by Savannah River Site studies that a lowering of the caustic solution $\mathrm{pH}$ to nearly equal to 10 (at the vapor-liquid interface) will take place by chemical reaction of the hydroxide with carbon dioxide over several months. The shift in $\mathrm{pH}$ makes this region vulnerable to pitting and possibly crevice corrosion (not yet observed). A 35 mils per year corrosion rate was determined at the liquid/vapor interface in a 1952 bismuth phosphate $\left(\mathrm{BiPO}_{4}\right.$ ) Hanford study (Schwenk and Divine 1993), but it is not certain how relevant this chemistry is to present day SSTs. The high pitting rate (similar to the pitting rates observed in the vapor phase) would result in complete penetration within seven years by Leakage Mechanism \#1. Recently, Savannah River Site personnel have been studying the nitrite inhibition of liquid/vapor pitting, but the studies have not yet determined the pitting rate. There is a shortage of corrosion rate data; consequently, there are inadequate data for assessing the time it would take to penetrate the wall by this mechanism.

\subsubsection{Stress Corrosion Cracking}

When the interface chemistry is outside the safe-operating specifications (see Appendix A, Table A-4) recommended by Ondrejcin et al (1979) and Kirch (1984), the potential for SCC cannot be ignored. Even though the bulk tank chemistry is within the Ondrejcin et al./Kirch specification, the interface composition may shift toward a $\mathrm{pH}$ and concentration regime where SCC is possible. Two scenarios can be hypothesized: a low hydroxide concentration (by reaction with carbon dioxide) with a high nitrate concentration; and a low hydroxide concentration and low nitrate and nitrite concentrations caused by dilution from condensation. Stress corrosion cracking has been observed to cause failure in the liquid phase of Savannah River Site double-shell waste tanks (Poe 1974 and Donovan 1977), and implicated as the principal failure mechanism of Hanford SSTs. Stress corrosion cracking is considered a high probability failure mechanism at this interface. Leakage Mechanism \#1 is the most likely cause. 


\subsubsection{Hydrogen Embrittlement (Vapor/Liquid and Vapor/Liquid/Solid Interface)}

The potential for HE to occur in the upper-level vapor/liquid and vapor/liquid/solid regions is low and appears unlikely. Since the interface is oxygenated, any cathodic reaction results in oxygen reduction rather than hydrogen evolution. Consequently, a major driving force for $\mathrm{HE}$ has been eliminated. One of the major hydrogen evolution poisons, $\mathrm{H}_{2} \mathrm{~S}$, that assists in the entry of hydrogen into the metal is not present. Tensile stresses from hydraulic loadings are low. Thus, most of the conditions leading to HE are not present.

\subsubsection{Uniform Corrosion}

Appendix A, Table A-1 indicates a maximum uniform ccrrosion rate of 1.6 mils per year (mpy) in nuclear waste environments at the liquid/vapor interface. Two recent Hanford studies show that the uniform corrosion iales are less than 1 mpy (Divine et al. 1985 and Danielson and Bunnel 1994). Therefore, uniform currosion is unlikely to cause leakage.

\subsubsection{Microbiologically Influenced Corrosion}

The literature provides no information on microbiological life in the waste tank environment. The microbiological bloom at Three Mile Island indicates that ionizing radiation is not an impediment to microbiological growth. Even if microbiological growth is possible in the waste tanks, it still remains to be determined if the metabolic products result in MIC. Consequently, the role of MIC as a failure mechanism is speculative.

\subsection{LIQUID REGION AND LIQUID/SOLID INTERFACE}

\subsubsection{Pitting and Crevice Corrosion}

Corrosion testing in Hanford waste tanks (see Appendix A, Table A-1) has detected pitting in the liquid phase. The highest rate was 6.4 mils per year (mpy), but there was a poorly substantiated case of $32 \mathrm{mpy}$. Ondrejcin estimated the pitting rate in the Savannah River Site evaporator coils was 1800 mpy when the waste was diluted. At this rate, wall penetration could occur in two months, and liquid phase pitting could be an important failure mechanism. Detailed knowledge of the tank chemistry is necessary to predict which tanks would be vulnerable. Since the tank wall breach is below the liquid level, immediate leaking would take place (Leakage Mechanism $\# 2$ ).

The salt cake environment was studied by Payer et al. (1975). The metal/salt interface resembles a crevice environment. No pitting or crevice corrosion was observed, but the 
hydroxide concentration was not allowed to decrease with time by reacting with carbon dioxide from the air to create the vulnerable condition. Pitting and crevice corrosion at the liquid/solid interface is speculative at this time.

\subsubsection{Stress Corrosion Cracking}

Stress corrosion cracking has been confirmed as a failure mechanism in the early Savannah River Site waste tanks that were not stress-relieved. Stress corrosion cracking has been frequently observed in laboratory studies when the chemistry falls outside of the recommended specifications (see Appendix A, Table A-4). Stress corrosion cracking was also observed in synthetic salt cake tests. Stress corrosion cracking is the best established failure mechanism for waste tanks.

\subsubsection{Hydrogen Embrittlement (Liquid Region and Liquid-Solid)}

The potential for HE in the lower regions of a given SST appears low principally because there does not appear to be a viable mechanism to generate high pressure hydrogen gas at the metal interface. Unlike the vapor and vapor/liquid regions, oxygen concentrations should be considerably lower which means that cathodic reactions would evolve hydrogen rather than react with oxygen. However, since the carbon steel is passive (very low corrosion rates), the driving force for hydrogen evolution would remain low.

As with the vapor region (see Section 2.1.3) and the near-water-line region (see Section 2.2.3), some conditions and assumptions are expected to be the same: no significant liner-concrete corrosion product buildup or significant loss of concrete, possible reduced weldment residual stresses, no detectable $\mathrm{H}_{2} \mathrm{~S}$ in the waste, long exposure time, and low material strength.

Some possible scenarios that could increase the potential for hydrogen damage are the following. The hydraulic pressure level has increased thereby slightly increasing the effect due to an increased hydrogen pressure. Dissolved oxygen level is probably low. Fluid temperatures are slightly higher; possible prior salt-bridging and localized dryout may have further increased the potential for local HE due to locally high temperatures. Stabilized SSTs contain highly concentrated fluids, and some probably contain an increased level of a poison like arsenic; an increased fluid poison level in conjunction with the normal metalloid poisons in carbon steel grain boundaries further coupled with potential differences approaching 0.5 volt between liquid and sludge phases (Bickford et al. 1980) increase the potential for HE. Stratification with horizons of widely differing hydroxide concentrations can create concentration cells which will generate voltage differences of the magnitude determined by Bickford et al. (1986). These voltage differences may act to generate hydrogen in one stratum. Bockris et al. (1986) indicate that cathodic polarization of a few hundred millivolts is enough to generate significant hydrogen concentrations in the metal. 


\subsubsection{Uniform Corrosion}

The early corrosion work at Hanford and the later testing of Divine et al. (1985) and Danielson et al. (1994) strongly indicate that uniform corrosion is not a viable failure mechanism.

\subsubsection{Microbiologically Influenced Corrosion}

The literature provides no information on microbiological life in the waste tank environment. The microbiological bloom at Three Mile Island indicates that ionizing radiation is not an impediment to microbiological growth. Even if microbiological growth is possible in the waste tanks, it remains to be determined if the metabolic products result in MIC.

Consequently, the role for MIC as a failure mechanism is speculative. 


\subsection{CORRELATION STUDIES (WASTE TYPE VERSUS ASSUMED LEAKER STATUS)}

Section 3.0 investigates waste type compositions in single-shell tanks (SSTs) (with assumed leaker status) to determine whether they have a relationship to the predicted solution compositions (see Section 2.0 and Appendix A, Table A-4) that are expected to cause failure of carbon steel by corrosion. Since the potential for hydrogen damage always appears low, hydrogen embrittlement (HE) is not included in the following discussion.

The SSTs were removed from active service in November 1980 and have not received additional wastes since that time. Before the tanks were retired, various waste volume reduction programs were undertaken to minimize the amount of occupied tank volume. These programs involved intertank transfers, evaporation, and chemical alterations of the waste. Kaiser Engineers Hanford Company has recently prepared a report of the Hanford Site SST level histories (KEH 1993). The various activities changed the character of the waste so that the actual waste composition is not known well enough to make informed decisions regarding disposal. According to Hill and Simpson (1994), there are 49 types of waste streams discharged to the SSTs at the Hanford Site. The majority of SSTs store more than one type of waste. These wastes have been categorized into 30 characteristic groups meaning that most waste groups contain more than one waste type. Although the tank contents were not deliberately mixed, gas evolution would result in some mixing.

The following discussion focuses primarily on waste groups in which all the tanks belonging to these groups leaked. Table 3-1 lists the waste groups, associated SSTs and the waste composition (nitrate relative to hydroxide). Although some waste groups contain more than two types of waste, Table 3-1 lists only the primary and secondary waste types. According to Hill and Simpson, primary and secondary waste types occupy most of the tank volume.

High-level waste from the reduction-oxidation (REDOX) process was stored in tanks 241-S104, 241-SX-107, 241-SX-108, 241-SX-109, 241-SX-112, 241-SX-115 and 241-U-101; all seven tanks have leaked. The waste contains high concentrations of nitrate $(4.83 \underline{\mathrm{M}})$ and a low concentration of hydroxide $(0.74 \underline{\mathrm{M}})$; no nitrite concentration was determined. However, some nitrite is expected to form since nitrate converts to nitrite from radiolysis. Based on the discussion in Section 2.0 and Appendix A, Table A-4, it is speculated that failures occurred by nitrate stress corrosion cracking (SCC) of the carbon steel liner because the hydroxide (and nitrite) inhibitor concentration was too low. Based on the work at the Savannah River Site, it is probable that much of the SCC occurred in the weld heat-affected zone.

Tanks 241-B-105, 241-TX-113, 241-TX-114, 241-TX-116, 241-TX-117 contain evaporator bottoms (EB) waste and first cycle decontamination waste (1C) with EB waste as the main constituent. All tanks have leaked. Waste type $1 \mathrm{C}$ has a nitrate $\left(\mathrm{NO}_{3}\right)$ concentration of $1.54 \mathrm{M}$ and $\mathrm{OH}+\mathrm{NO}_{2}$ (hydroxide + nitrite) of $0.56 \mathrm{M}$ which is only slightly less than the recommended safe operating limit of $0.4\left[\mathrm{NO}_{3}\right]$ of $0.62 \mathrm{M}$. The EB waste has a very high 
Table 3-1. Relationship Between Tank Failure and Waste Composition for the Single-Shell Tanks*.

\begin{tabular}{|c|c|c|c|}
\hline $\begin{array}{l}\text { Waste groupl" } \\
\text { vaste ypo': }\end{array}$ & Tanks & (i. & Comments \\
\hline REDOX & $\begin{array}{l}\text { S-104, SX-107, SX-108, } \\
\text { SX-109, SX-112, } \\
\text { SX-115, U-101 }\end{array}$ & 100 & High nitrate/low $\mathrm{OH}$ \\
\hline $\mathrm{HS}$ & $\begin{array}{l}\text { C-201, C-202, C-203, } \\
\text { C-204 }\end{array}$ & 100 & $\begin{array}{l}\text { Composition meets tank waste } \\
\text { specifications }\end{array}$ \\
\hline $2 C, 5-6$ & B-110, B-111, B-112 & 100 & Possibly high nitrate/low $\mathrm{OH}$ \\
\hline REDOX, REDOX-IX & $\begin{array}{l}\text { SX-110, SX-111, } \\
\text { SX-114 }\end{array}$ & 100 & High nitrate/low $\mathrm{OH}$ \\
\hline 1C, EB-ITS & $\mathrm{BX}-110, \mathrm{BX}-111$ & 100 & High nitrate/low $\mathrm{OH}$ \\
\hline TBP & TY-105, TY-106 & 100 & Extremely high nitrate/low $\mathrm{OH}$ \\
\hline TBP, $1 \mathrm{C}-\mathrm{F}$ & TY-103, TY-104 & 100 & Very high nitrate/low $\mathrm{OH}$ \\
\hline REDOX, DIA & $S X-113, U-104$ & 100 & Fairly high nitrate/low $\mathrm{OH}$ \\
\hline
\end{tabular}

*Waste grouping for the SSTs is based on Hill and Simpson (1994).

sodium nitrate concentration $\left(\mathrm{NaNO}_{3} 73.8 \mathrm{wt} \%\right)$ and a low $\mathrm{OH}$ concentration. Consequently, the blending of these wastes may have led to a high $\mathrm{NO}_{3}$ and a low $\mathrm{OH}$ concentration waste which exceeds safe operating conditions (low in $\mathrm{OH}$ and nitrite inhibitor concentration). Another possibility is that the two process streams did not mix, and a horizon of the EB waste was formed containing inadequate concentrations of the nitrite inhibitor. Since the nitrate concentration is high, it is probable that the tanks failed by nitrate SCC of the carbon steel liner. This group of tanks also includes tanks 241-TX-109, 110, and 111 which store three types of wastes: ${ }^{-} \mathrm{BB}, 1 \mathrm{C}$, and tributyl phosphate (TBP). In these tanks, EB and $1 \mathrm{C}$ are the primary and secondary waste types. Although the TBP waste contains high nitrate concentrations and low $\mathrm{OH}$ concentrations, which probably places them in an unsafe chemical regime, only tank $241-\mathrm{TX}-110$ has leaked. It is probable that the remaining two tanks are vulnerable to a SCC failure and subsequent leaking.

Tanks 241-B-110, 111, and 112 belong to a group of tanks containing second cycle decontamination waste (2C) and waste from tank 5-6 at B Plant. The primary waste type is $2 \mathrm{C}$, the second decontamination cycle of the bismuth phosphate process at $\mathrm{B}$ and $\mathrm{T}$ plants. It is the effluent that remains after precipitation of plutonium. The nitrate concentiation of this waste is $1.27 \underline{\mathrm{M}}$ with no listed concentration data for $\mathrm{OH}$ or $\mathrm{NO}_{2}$. Waste type 5-6 collected at the bottom of Section 5 at B plant due to boil-over during the dissolving and neutralization 
steps of the bismuth phosphate process. It is believed that the waste has a high concentration of nitrate. Since all three tanks have leaked, it is speculated that the tank failure mechanism was nitrate SCC.

Tanks 241-C-201, 241-C-202, 241-C-203 and 241-C-204 store waste from the hot semiworks plant. This plant ran several strontium extraction campaigns from 1955 to 1961 which discharged 50,000 gallons of dilute wastes to Tank Farms. The waste composition is assumed to be similar to that of the strontium semiworks waste, i.e., 2.1M nitrate $\left(\mathrm{NO}_{3}\right)$, $1.32 \mathrm{M} \mathrm{OH}$ with no reported results for $\mathrm{NO}_{2}$. This means $\left(\mathrm{OH}+\mathrm{NO}_{2}\right)$ concentration is greater than $0.4\left[\mathrm{NO}_{3}\right]$; thereby, exceeding the mirimum safe operating level required for immunity from nitrate SCC (see Appendix A, Table A-4). On this basis, the tanks containing waste from the hot semiworks plant are not expected to aggressively corrode by SCC or pitting. However, all four tanks containing this waste have been reported as leakers. It is probable that stratification led to settling of the nitrate to the bottom waste layers of the tank, thus lowering the $\left(\mathrm{OH}+\mathrm{NO}_{2}\right)$ concentration to well below the $0.4\left[\mathrm{NO}_{3}\right]$ required by the waste tank specifications. This is a valid reason for core sampling SST wastes, to determine composition as a function of depth in the tank. To validate the above hypothesis, inspection of the tank outer wall may be required to determine the location of the tank leak.

Tanks 241-SX-111, 241-SX-110 and 241-SX-114, which store REDOX waste and REDOX ion exchange (REDOX-IX) waste, have leaked. REDOX waste is primary. It is characterized as having high $\mathrm{NO}_{3}$ concentration. The $\left(\mathrm{OH}+\mathrm{NO}_{2}\right)$ concentration is lower than $0.4\left[\mathrm{NO}_{3}\right]$ indicating it is in the unsafe regime for nitrate SCC (see Appendix $\mathrm{A}$, Table A-4). The REDOX-IX waste, which is secondary, contains $\left(\mathrm{OH}+\mathrm{NO}_{2}\right)$ slightly greater than the $0.4\left[\mathrm{NO}_{3}\right]$ recommendation, placing it in the safe regime by a narrow margin. It is hypothesized that there is insufficient REDOX-IX waste to adjust the combined composition into the safe regime; therefore, it is probable that the tanks failed by nitrate-induced SCC.

Tanks $241-\mathrm{BX}-110$ and $241-\mathrm{BX}-111$ belong to a group used to store waste types $1 \mathrm{C}$ and evaporator bottoms - in-tank solidification (EB-ITS). As mentioned earlier, 1C waste has high nitrate and low OH concentrations, while EB-ITS is expected to have similar high nitrate and low $\mathrm{OH}$ concentrations as the EB waste. Both tanks are assumed leakers, which is consistent with the high nitrate and low inhibitor concentrations leading to nitrate SCC.

Tanks 241-TY-105 and 241-TY-106 store only TBP waste; both have leaked. As discussed earlier, the TBP waste contains high concentrations of nitrate with inadequate amounts of $\mathrm{OH}$ to provide an inhibiting effect (see Appendix A, Table A-4). Two other tanks from the TY Farm, 241-TY-103 and 241-TY-104, contain TBP as primary and 1C-ferrocyanide scavenged waste (1C-F) as secondary; both are assumed leakers. This is consistent with the high nitrate and low $\mathrm{OH}$ concentration of waste that results in nitrate SCC.

Tank 241-TY-103 also contains cladding waste (tertiary waste type), and a combination of REDOX (R) and MIX (REDOX-MIX). In addition to TBP and 1C-F, Tank 241-TY-104 contains decontamination waste as the tertiary waste type and MIX-REDOX. 
Tanks 241-SX-113 and 241-U-104 contain waste types REDOX and diatomaceous earth (DIA); both have leaked. As indicated earlier, waste type REDOX has high nitrate concentrations with inadequate amounts of $\mathrm{OH}$ to provide the inhibiting action. Nitrate SCC is the likely failure mechanism.

Most of the situations discussed in Section 3.0 have inadequately characterized chemistries. A common theme to the leakers is high nitrate concentrations, low hydroxide concentrations, and little or no nitrite. Both hydroxide and nitrite are required to inhibit nitrate SCC, and the formula for nitrate SCC immunity (see Appendix A, Table A-4; is a clear statement of those conditions. Hydroxide alone is not totally adequate. Nitrite also has an important role, but none was present initially. Inhibition of nitrate SCC had to wait until radiolytic processes created sufficient concentrations of nitrite; consequently, the tanks were most vulnerable to nitrate SCC when first filled. 


\subsection{CONCLUSIONS}

There is ample evidence to make a strong case for the stress corrosion cracking (SCC) failure of the single-shell tanks (SSTs) in the vapor/liquid, liquid/solid, and liquid phases. The single strongest evidence for SCC is a failure analysis carried out at the Savannah River Site where non-stress-relieved double-shell tanks leaked. However, pitting and possibly crevice corrosion cannot be discounted as a cause of tank leaks. The literature supports observations that high pit propagation rates would lead to penetration of the tank wall at the vapor, liquid/solid, and liquid phases. However, a failure analysis has never been performed to confirm the pitting failure mechanism on SSTs. Uniform corrosion remains the most benign degradation process and is the least likely to result in a tank leak. Although microbiologically influenced corrosion has been reported to occur at the Savannah River Site and the Hanford Site, it is not considered to be a viable mechanism for SST failure. None of the various hydrogen damage mechanisms appear likely to occur. However, the region of greatest probability of occurrence is believed to be in the liquid/sludge (solid) regions near the tank bottom. There are three major limitations to assessing the likelihood of failure of SSTs at Hanford:

1. There is a lack of chemical composition data for the SSTs. Long term predictions of tank performance cannot be made without these data. Further, the details that must be defined in a laboratory study to support a long-term performance prediction become impossible to carry out without composition information.

Waste tank degradation can be minimized by controlling the waste chemistry. Bulk inhibitor additions can be made directly to the tanks to begin retarding SCC and pitting. However, accurate control of chemistry cannot be completely achieved without first mixing the stratified waste to assure homogeneity.

2. Predictions for time to failure for each potential failure mechanism cannot be made without rate data. There is a hint in the literature that pitting rates decrease with time, but tests were never done with sufficient time to support this hypothesis. There is a very limited amount of SCC crack growth rate data, including threshold stress intensity levels $\left(\mathrm{K}_{\mathrm{lacc}}\right)$, upon which a SCC prediction can be made or that a stress analyst can use as design parameters.

3. No failure analyses have been carried out on any SSTs at Hanford to clearly identify the failure modes. 
This page intentionally left blank. 


\subsection{RECOMMENDATIONS}

To control or mitigate corrosion, the methods usually employed are material selection, application of coatings, environment modification, and cathodic protection. It is too late to adopt all these options except for environment modification (chemistry adjustment) for Hanford single-shell tanks (SSTs). The following recommendations are made to mitigate waste tank corrosion and to minimize leaks to the surrounding soil.

\subsection{SPECIFIC RECOMMENDATIONS}

Recommendations are made to control corrosion and to help resolve outstanding unreviewed safety questions (USQs). The methodology for selecting SSTs appropriate for specific recommendations is as follows:

Only sound, non-stabilized tanks are considered for the specific recommendations and for immediate action by the U.S. Department of Energy (DOE). These tanks are underlined for all the waste groups listed in Table 5-1. Leaking tanks and stabilized tanks are not included. An aggressiveness or corrosivity factor (CF) is calculated for each waste group in Table 5-1. The factor in each case is the ratio of $\mathrm{NO}_{3}{ }^{-}$to $\mathrm{OH}+\mathrm{NO}_{2}$. The approximate anion concentrations for each waste type are obtained from Hill and Simpson (1994). For all waste groups, only the primary and secondary waste types are considered for the CF calculations. It is also assumed here that the primary waste type occupies 70 percent of the waste volume, while the secondary waste type occupies the remaining 30 percent of the volume for the waste group. In addition, the $\mathrm{CF}$ is assumed to be the same for each tank within a given waste group in the absence of any characterization data. The critical CF, above which the waste environment is considered to be aggressive from a corrosion standpoint, is 2.5 (calculated from double-shell tank [DST] corrosion specifications).

The CFs for the various waste types are given in Table 5-2. The composite CFs for the waste groups were calculated from the $\mathrm{CF}$ values for the individual waste types. The $\mathrm{CF}$ for evaporator bottoms-in-tank solidification (EB-ITS) waste type is assumed to be 35 , which is greater than the CF of 30.28 for evaporator bottoms (EB). This is because the waste type EB-ITS is considered more concentrated than waste type EB. The composite CFs for all the waste groups are given in Table 5-1, which shows the CFs range from a minimum value of 0.77 to a maximum value of 81.67 . For this analysis, all the sound non-stabilized tanks not meeting the waste tank specifications are considered for future action.

Table 5-1 also lists the priority for all the waste groups containing the sound non-stabilized tanks. Although the $\mathrm{CF}$ is greater than 2.5 for several of the other waste groups, no priority has been assigned to these groups for which there is no immediate action. 
Table 5-1 shows that no immediate action is recommended also for waste groups containing sound non-stabilized tanks with a $\mathrm{CF}<2.5$. These waste groups have been assigned a priority of 11 and 12 respectively.

Table 5-1. Waste Grouping Versus Leak Status for the Single-Shell Tanks*.

(2 sheets)

\begin{tabular}{|c|c|c|c|c|c|}
\hline Pronis & 10.6010010 & Tanks & porodod & $\mathrm{CF}^{*}$ & Comments \\
\hline 1 & TBP, EB-ITS & BY -109, BY -102 & 0 & 67.67 & Pump liquid \\
\hline 2 & TBP, CW & $\begin{array}{l}\mathrm{BX}-101, \mathrm{BX}-102, \mathrm{BX}-103, \mathrm{BX}-104, \\
\mathrm{BX}-105, \mathrm{BX}-106, \mathrm{C}-101\end{array}$ & 43 & 57.18 & Pump liquid \\
\hline 3 & $\mathrm{CW}, \mathrm{TBP}$ & $\underline{C}-102, \underline{C-105}$ & 0 & 24.54 & Pump liquid \\
\hline 4 & SS, TBP & $\underline{C-103}, \underline{C-106}$ & 0 & 24.53 & Pump liquid \\
\hline 5 & EB, REDOX & $\underline{U}-103, \underline{U-102}, \underline{U-111}, \underline{U-106}, \mathrm{TX}-115$ & 20 & 23.16 & Add $\mathrm{NaOH}$ \\
\hline 6 & $\mathrm{~EB}, \mathrm{CW}$ & $\underline{\mathrm{U}}-105, \underline{\mathrm{U}-107}, \underline{\mathrm{U}-108}, \underline{\mathrm{U}-109}$ & 0 & 21.21 & Add $\mathrm{NaOH}$ \\
\hline 7 & REDOX, EB & $\begin{array}{l}\frac{S-102}{S-108}, \frac{S-111}{S-110}, \frac{S-106}{S-112}, \frac{S-105}{S-103}, \frac{S-109}{S-101}, \\
\frac{S-107}{S X-102}, \frac{S X-105}{S X-101}, \frac{S X-106}{S X-102}, \frac{T X}{T X}, 104 \\
\frac{T X-105}{T X-106}, T X-107\end{array}$ & 14 & 13.66 & $\begin{array}{l}\text { Add } \mathrm{NaOH} \\
\text { (S Farm) } \\
\text { Install probe } \\
\text { (SX Farm) }\end{array}$ \\
\hline $\begin{array}{l}11 \\
8 \\
10\end{array}$ & Ungrouped & $\begin{array}{l}\text { A-104, A-105, A-106, AX-104, B-104, } \\
\text { BX-109, C-104, C-107, } \\
\text { SX-103, T-109, } \\
\frac{T-104}{T-T X-101, ~ T X-103, ~ T X-112, ~} \\
\text { TY-101, U-110, U-112, U-204 }\end{array}$ & 39 & $\begin{array}{c}0.85 \text { for } \\
\text { C-107 } \\
4.87 \text { for } \\
\text { SX-103 } \\
2.75 \text { for } \\
\text { T-104 }\end{array}$ & $\begin{array}{l}\text { No imm. action } \\
\text { Install probe } \\
\text { Install probe }\end{array}$ \\
\hline 9 & $2 C, 224$ & $\mathrm{~T}-110, \mathrm{~T}-111, \mathrm{~T}-112$ & 33 & 4.04 & Install probe \\
\hline 12 & DSSF, NCPLX & A-101, A-102, A-103, AX-101 & 25 & 0.77 & No imm. action \\
\hline N/A & REDOX & $\begin{array}{l}S-104, S X-107, S X-108, S X-109 \\
S X-112, S X-115, U-101\end{array}$ & 100 & 6.53 & No imm. action \\
\hline N/A & HS & C-201, C-202, C-203, C-204 & 100 & 1.59 & No imm. action \\
\hline N/A & $2 C, 5-6$ & B-110, B-111, B-112 & 100 & 5.00 & No imm. action \\
\hline N/A & $\begin{array}{l}\text { REDOX, } \\
\text { REDOX-LX }\end{array}$ & $S X-110, S X-111, S X-114$ & 100 & 6.07 & No imm. action \\
\hline N/A & $1 \mathrm{C}, \mathrm{EB}-\mathrm{ITS}$ & $\mathrm{BX}-110, \mathrm{BX}-111$ & 100 & 12.43 & No imm. action \\
\hline N/A & TBP & TY-105, TY-106 & 100 & 81.67 & No imm. action \\
\hline N/A & TBP, 1C-F & TY-103, TY-104 & 100 & 57.99 & No imm. action \\
\hline N/A & REDOX, DIA & SX-113, U-104 & 100 & 4.57 & No imm. action \\
\hline
\end{tabular}


Table 5-1. Waste Grouping Versus Leak Status for the Single-Shell Tanks*.

(2 sheets)

\begin{tabular}{|c|c|c|c|c|c|}
\hline Priority & $\begin{array}{l}\text { Wasto groupt } \\
\text { waste typt }\end{array}$ & Tanks: & $\begin{array}{l}\text { Percent } \\
\text { leaked }\end{array}$ & $C F^{* *}$ & Comments \\
\hline$N / A$ & $\mathrm{~EB}, 1 \mathrm{C}$ & $\begin{array}{l}\text { B-105, TX-109, TX-110, TX-111, } \\
\text { TX-113, TX-114, TX-116, TX-117, } \\
\text { TY }-102\end{array}$ & 75 & 22.02 & No imm. action \\
\hline N/A & $\mathrm{CW}, \mathrm{EB}$ & B-101, B-102, B-103 & 67 & 9.12 & No imm. action \\
\hline N/A & CW, MDX & $\mathrm{T}-101, \mathrm{~T}-102, \mathrm{~T}-103$ & 67 & .10 & No imm. action \\
\hline N/A & 1C, TBP & $\mathrm{B}-106, \mathrm{BX}-107, \mathrm{BX}-108, \mathrm{C}-110, \mathrm{~T}-108$ & 60 & 26.43 & No imm. action \\
\hline N/A & TBP-F, EB-ITS & $\begin{array}{l}\text { BY }-101, \mathrm{BY}-103, \mathrm{BY}-104, \mathrm{BY}-105, \\
\mathrm{BY}-106, \mathrm{BY}-107, \mathrm{BY}-108, \mathrm{BY}-110, \\
\mathrm{BY}-111, \mathrm{BY}-112\end{array}$ & 50 & 45.5 & No imm. action \\
\hline N/A & CCPLX, DSSF & $A X-102, A X-103$ & 50 & 1.10 & No imm. action \\
\hline N/A & $1 \mathrm{C}, \mathrm{CW}$ & $T-105, T-100$ & 50 & 1.94 & No imm. action \\
\hline N/A & TBP-F, $1 \mathrm{C}$ & C-108, C-109, C-111, C-112, T-107 & 40 & 35.83 & No imm. action \\
\hline N/A & 224 & $\begin{array}{l}\text { B-201, B-202, B-203, B-204, T-201, } \\
\text { T-202, T-203, T-204 }\end{array}$ & 37.5 & 1.80 & No imm. action \\
\hline N/A & $1 \mathrm{C}, \mathrm{EB}$ & B-107, B-108, B-109, BX-112 & 25 & 11.01 & No imm. action \\
\hline N/A & $\mathrm{CW}$ & $\mathrm{U}-201, \mathrm{U}-202, \mathrm{U}-203$ & 0 & 0.05 & No imm. action \\
\hline N/A & EB, TBP & TX-108, TX-118 & 0 & 45.70 & No imm. action \\
\hline
\end{tabular}

*Waste grouping for the SSTs is based on Hill and Simpson (1994).

**Corrosivity Factor $(\mathrm{CF})$ is the concentration ratio $\left[\mathrm{NO}, \mid /\left[\mathrm{OH}+\mathrm{NO}_{2}\right]\right.$. It is calculated for all waste groups. However, action is recommended for sound non-stabilized tanks only. These tanks are underlined and arranged in decreasing order of amount of drainable liquid remaining within each waste tank. The critical CF is $\mathbf{2 . 5}$ above which the waste is considered to be aggressive to carbon steel from a corrosion standpoint. 
Table 5-2. Corrosivity Factors for the Waste Types Used in Assigning Priorities.

\begin{tabular}{|c|c|c|c|}
\hline Waste type & $\begin{array}{l}\mathrm{OH}+\mathrm{NO}_{2} \\
\text { molestliter }\end{array}$ & $\begin{array}{c}\mathrm{NO}_{3} \\
\text { moles/liter }\end{array}$ & $\begin{array}{l}\text { Corrosivity factor } \\
\mathrm{NO}_{3} /\left(\mathrm{OH}+\mathrm{NO}_{2}\right)\end{array}$ \\
\hline REDOX & 0.74 & 4.83 & 6.53 \\
\hline HS & 1.32 & 2.1 & 1.59 \\
\hline $2 C$ & NR & 1.27 & $5^{\circ}$ \\
\hline OWW & NR & 0.06 & $1^{\bullet}$ \\
\hline $1 \mathrm{C}$ & 0.56 & 1.54 & 2.75 \\
\hline $\mathrm{EB}^{* \bullet}$ & 0.57 & 17.26 & 30.28 \\
\hline TBP & 0.09 & 7.35 & 81.67 \\
\hline $\mathrm{CW}$ & 0.37 & 0.02 & 0.05 \\
\hline CCPLX & 0.52 & 0.72 & 1.38 \\
\hline DSSF & 6.05 & 2.72 & 0.45 \\
\hline 224 & 0.59 & 1.06 & 1.8 \\
\hline NCPLX & 2.2 & 3.3 & 1.5 \\
\hline SS & 5.74 & NR & $0.04^{\circ}$ \\
\hline
\end{tabular}

Future action is recommended in three important areas. For each area, the tanks belonging to a tank farm within a given waste group on which action is required are arranged in decreasing order of the amount of drainable liquid remaining.

Recommendation \#1: Expedite Stabilization Remove as much liquid as possible from nonstabilized sound tanks containing the most aggressive waste under consideration. The liquid removal is expected to be accomplished by first stabilizing and then by forced evaporation (if possible) from the following tanks: BY-109, BY-102, BX-106, C-102, C-105, C-103 and C-106. Options should be considered to reduce condensation. Kaiser Engineers Hanford Company (KEH) has recently developed a pumping strategy for Hanford Site SST interim stabilization based on other criteria (KEH 1994). There is a fair agreement between the present pumping recommendation and $\mathrm{KEH}$ pumping strategy. 
Recommendation \#2: Addition of Corrosion Inhibitor Add a corrosion inhibitor (e.g., sodium hydroxide) to assure that the open circuit corrosion potential for the carbon steel tank, storing the given waste types, is in the passive region to mitigate accelerated degradation of the tank. This recommendation is for sound tanks that are not going to be interim stabilized in the near future and are suspected of having liquids that do not meet the tank waste specifications. These tanks include the following: U-103, U-102, U-111, U-106, U-108, U-109, U-105, U-107, S-102, S-111, S-106, S-109, S-108, S-110, S-112, S-103, S-101 and S-107.

Recommendation \#3: Installation of Corrosion Monitoring Probes Install corrosion monitoring probes and/or coupons (preferably to monitor stress corrosion cracking [SCC]) in the sound non-stabilized tanks containing wastes not meeting tank waste specifications. Corrosion monitoring probes can be installed in the salt cake to monitor the corrosivity of the interstitial liquid. Of utmost importance is the development of SCC monitoring probes. These probes can be wedge-open-loaded compact tension specimens that would (pre-cracked and stressed) be inserted into the tanks, then periodically removed to measure the crack extension rate. These tanks include the following: SX-105, SX-106, SX-102, SX-101, $\mathrm{SX}-103, \mathrm{~T}-110$ and $\mathrm{T}-104$. They are similar to tanks discussed above for inhibitor addition, but they are on a lower priority for adding inhibitors due to lower CFs.

\subsection{GENERAL RECOMMENDATIONS}

General recommendations are described in the subsections below.

\subsubsection{Characterization}

It is necessary to determine the chemical composition of waste in each SST. Conceivably, the waste is stratified so that the composition varies by horizon. Waste stratification could set up electrochemical concentration cells that can drive various failure mechanisms (i.e., SCC, pitting, and hydrogen embrittlement [HE]). Radiation dose rate must also be known since this can affect the electrochemical potential. Both SCC and pitting are strongly affected by the electrochemical potential.

Sample and characterize condensate trickling down the walls of the SSTs.

\subsubsection{Failure Analysis}

Although the construction of the SSTs prohibits a classical failure analysis (where the failed area is cut out and studied) of the known leakers, this knowledge is vital for focusing on the relevant failure mechanism(s). It is recommended that vapor, vapor/liquid, and vapor/solid regions be examined with remote video equipment, which has the capabihity of high-pressure 
washing of the wall deposits, to visually assess if SCC, pitting, and crevice attack have penetrated the wall. The physical dimensions should be measured, and samples of adjacent deposits should be taken.

\subsubsection{Laboratory Testing}

To predict future performance, the rates of the potential failure mechanisms must be determined. Once the tank waste chemical composition is known, a statistically based test matrix of solutions can be defined. These solutions will enable the experimental determination of the effects of composition on failure mechanisms. Testing should include vapor, liquid, and solid phases. A temperature of $97^{\circ} \mathrm{C}$ is suggested to minimize the cost associated with autoclaves (elevated pressure test vessels).

1. SCC Testing. The only way to determine the propensity for SCC is to start a crack growing by cyclic fatigue, then to change to constant $\mathrm{K}$ (stress intensity) to ascertain whether the crack continues to grow. This is the most conservative approach because there is no initiation phase to the process . Crack growth rates as a function of $\mathrm{K}$ should be determined in each solution composition or specialized environment. The threshold stress intensity $\left(\mathrm{K}_{\mathrm{ISCC}}\right)$ should also be determined.

The effect of radiation anodically polarizes the carbon steel and possibly increases the likelihood of SCC. The effects of the radiation dose rate on the open circuit corrosion potential should be assessed in each solution, and SCC testing should be carried out at these electrochemical potentials through the use of potentiostats to control the potential.

2. Pitting and Crevice Testing. Testing must focus on determining the rate as a function of composition. There is presently no real-time method for the experimental measurement of pitting rates; pit depths and diameters must be determined by direct physical measurement (i.e., optical methods or by depth micrometer). Efforts should be devoted to developing a method for measuring real-time pit growth rates. Pit growth rate measurements should be carried out for at least two years to determine how the pitting rate changes with time. Testing should be carried out in the same environments as the SCC testing. Crevice corrosion can be studied in real-time; useful data can be achieved in shorter periods.

3. Uniform Corrosion. The present database appears adequate for predictive purposes; no additional work is needed. This may need to be reviewed if future waste composition data indicate major differences from past compositions. 
4. Hydrogen Damage. Liner degradation or failure by any hydrogen damage mechanism appears a low probability. No test plan for $\mathrm{HE}$ is recommended at this time. If future removal and metallurgical/hydrogen analysis of cracked or leaking regions of SSTs indicates the possibility of hydrogen damage, revision of the test plans may be in order.

5. Waterline Corrosion. The waterline corrosion can be experimentally studied for the Hanford tank wastes by exposing carbon steel specimens prototypic of SST liner steel in simulated wastes of $\mathrm{pH}$ ranging from 6 to 13. The studies should include both initiation and propagation of pitting. The data obtained can be analyzed for pitting initiation times and pit growth rates as a function of $\mathrm{pH}$ of the waste. This work was initiated at the National Institute for Standards and Testing in Fiscal Year 1993 but has been placed on hold. 
WHC-EP-0772

This page intentionally left blank. 


\subsection{REFERENCES}

Bickford, D. F., J. W. Congdon, and S. B. Oblath, 1986, "Electrochemical Probing of High-Level Radioactive Waste Tanks Containing Washed Sludge and Precipitates", DP-MS-86-178, E. I. duPont de Nemours and Company, Savannah River Site, Aiken, South Carolina.

Bockris, J. O'M., B. F. Conway, E. Yeager, and R. E. White, 1981, "Comprehensive Treatise of Electrochemistry," Vol. 4, Plenum Books, New York.

Danielson, M. J., and L. R. Bunnell, 1994, "Sludge Washing Materials Study: The Behavior of Carbon Steel in a Dilute Waste Environment," TWRS PP-94-025, Pacific Northwest Laboratory, Richland, Washington.

Divine, J. R., W. M. Bowen, D. R. Mackey, D. J. Bates, and K. H. Pool, 1985, "Prediction Equations for Corrosion Rates of A-537 and A-516 Steels in Double Shell Slurry, Future Purex, and Hanford Facilities Wastes," PNL-5488, Pacific Northwest Laboratory, Richland, Washington.

Donovan, J. A., 1977, "Materials Aspects of SRP Waste Storage--Corrosion and Mechanical Failure," DP-1476, E. I. duPont de Nemours and Company, Savannah River Site, Aiken, South Carolina.

Hill, J.G. and B.C. Simpson, 1994, The Sort on Radioactive Waste Type Model: A Method to Sort Single-Shell Tanks into Characteristic Groups, PNL-9814, Pacific Northwest Laboratory, Richland, Washington.

KEH, 1993, "Hanford Site Single-Shell Tank Level Histories for Corrosion Analysis, WHC-SD-WM-ER-209, Rev. 0, Westinghouse Hanford Company, Richland, Washington.

KEH, 1994, "Development and Determination of a Single-Shell Tank Interim Stabilization Pumping Strategy," WHC-SD-WM-ES-305, Rev. 0, Westinghouse Hanford Company, Richland, Washington.

Kirch, N. W., 1984, Technical Basis for Waste Tank Corrosion Specifications, SD-WM-TI-150, Rockwell Hanford Operations, Richland, Washington.

Ondrejcin, R. S., S. P. Rideout, and J. A. Donovan, 1979, "Control of Stress Corrosion Cracking in Storage Tanks Containing Radioactive Waste," Nuclear Technology, Vol. 44, pp. 297-306.

Payer, J. H., R. B. Diegle, and W. K. Boyd, 1975, Corrosivity of Synthetic Salt Cake, ARC-C-22, Battelle Columbus Laboratories, Columbus, Ohio. 
Poe, W. L., 1974, "Leakage of Waste Tank 16: Amount, Fate, and Impact," DP-1358, E. I. duPont de Nemours and Company, Savannah River Site, Aiken, South Carolina.

Public Law 101-510, Section 3137, "Safety Measure for waste Tanks at Hanford Nuclear Reservation," (the Safety Measures Law), Washington, D.C. 1990.

Schwenk, E. B., and J. R. Divine, 1993, "Proposed Corrosion Assessment of Hanford Waste Storage Tanks in Support of Interim Safety Basis Report, " EBS-93-009, Westinghouse Hanford Company, Richland, Washington. 
WHC-EP-0772

APPENDIX A

REVIEW OF CARBON STEEL CORROSION LITERATURE

A-1 
This page intentionally left blank. 


\section{A.1 PITTING}

\section{A.1.1 Pitting Experience Outside the Nuclear Industry}

Pits result from a highly localized corrosion process that produces small diameter holes in a solid metal structure. In time, complete penetration and leaking is possible. Pits usually begin at MnS (manganese sulfide) precipitates prevalent in carbon steels (Smialowska 1986). Once a pit begins, the local chemistry in the pit develops in an autocatalytic manner to sustain the high corrosion rate. Crevice corrosion shares the same propagation mechanism with pitting, but the beginning stages are different. The severity of pitting strongly depends upon the identity and concentration of aggressive ions in solution (Smialowska 1986). The chloride ion is one of the most potent, but other halide ions are also aggressive. Many substances act as pitting inhibitors for carbon steels, e.g., sulfate, nitrate, nitrite, carbonate, hydroxyl, and ammonium ions. An interrelationship between the concentrations of the aggressive ion and the concentration of the inhibiting species determines whether pitting will actually occur. A review by Claiborne et al. (1985) on the behavior of carbon steels in a waste repository points out that the propensity for pitting increases as the temperature and concentration of the aggressive ion increases. The presence of an oxygen containing environment, also important, polarizes the metal surface into an anodic electrochemical potential regime. Pitting propensity can be characterized by a threshold electrochemical potential ( $E_{p}$, pitting potential) which must be exceeded in the anodic direction (more positive) for pitting to occur. Pitting potential is a function of the aggressive ion concentration and has the following functionality (Smialowska 1986):

$$
E_{p}=A-B * \log \left(C_{x}\right)
$$

Where
$\mathrm{A}=$ Experimentally determined electrochemical potential
$\mathrm{B}=0.06$ to 0.2 volts (experimentally determined)
$\mathrm{C}_{\mathrm{x}}=$ Aggressive ion concentration

Although it is not apparent from Equation 1, there is a threshold concentration for the aggressive ion below which no pitting will occur. A metal can be maintained in a state of immunity by controlling the electrochemical potential and concentration of the aggressive ion(s). 
If the chloride ion $\left(\mathrm{Cl}^{-}\right)$concentration is held below $10^{-3} \mathrm{M}$, carbon steel in an environment with a $\mathrm{pH}$ value greater than 10 is passive and does not pit (Kaesche 1985). However, at pH values near 9 and below, pitting is observed in air-saturated conditions at these low $\mathrm{Cl}^{\circ}$ concentrations. Strehblow and Titze (1977) observe that, at $\mathrm{pH} 5$, pitting is found throughout the passive electrochemical potential state, but that no pitting potential was observed. This means that the open circuit corrosion potential is anodic or above the pitting potential. Awad and Hoar (1975) observed pitting (bicarbonate and carbonate solutions) at $\mathrm{pH} 8.3$ in $0.05 \mathrm{M} \mathrm{Cl}^{-}$but not at $\mathrm{pH} 11.6$. In a $\mathrm{pH} 12$ solution, Venu et al. (1965) found pitting in $0.1 \mathrm{M} \mathrm{Cl}^{-}$but not in $0.01 \mathrm{M}$. Clearly, carbon steels are prone to pitting in oxygenated solutions containing chloride, but hydroxide can act as an inhibitor. Matsuda and Uhlig (1964) investigated the effect of chromate and nitrite on the pitting inhibition in chloride-containing solutions. In a $\mathrm{Cl}^{-}$concentration range of $10^{-2}$ to $10^{-4} \mathrm{M}$, nitrite was a strong inhibitor in room temperature solutions that were air-saturated. No pitting was observed when $\left[\mathrm{Cl}^{-}\right] /\left[\mathrm{NO}_{2}{ }^{-}\right]$is less than or equal to 10.3. Strehblow and Titze (1977) investigated the inhibiting effects of nitrate on chloride-induced pitting and found the following relationship on the pitting potential at $\mathrm{pH} 8$ :

$$
\mathrm{E}_{\mathrm{p}}(\mathrm{SHE}, \text { volt })=0.98-(0.31) * \log \left(\left[\mathrm{Cl}^{-} \mathrm{U}^{-}\left[\mathrm{NO}_{3}^{-}\right]\right)\right.
$$

Where

$$
\text { SHE }=\text { Standard Hydrogen Electrode Potential Scale }
$$

Since the open circuit potential is estimated at approximately -0.5 volts, nitrate is a very potent inhibitor. There were no citations found in the non-nuclear literature indicating that nitrate can act as an agent to cause pitting; however, recent nuclear waste storage tank work has found such a relationship for nitrate (Zapp and Hobbs 1992). Nitrite concentrations below about 500 parts per million at a $\mathrm{pH}$ greater than 7.5 have been associated with pitting (Metals Handbook 1987).

\section{A.1.2 Pitting Corrosion Data on Carbon Steel Nuclear Waste Storage Tanks}

Schwenk and Divine (1993) comprehensively reviewed the historical Hanford corrosion test data from 1949 to 1987 as a basis for a future corrosion assessment of single-shell tanks (SSTs) and double-shell tanks (DSTs) (see Table A-1). Table A-1 groups data by waste type and testing date. It is important to note that some of the historical coupon testing was carried out in SSTs. In general, pitting was often observed on specimens exposed to the vapor and liquid phases, but the rates rarely exceeded 4 mils per year (mpy). In a few cases, the pitting rate exceeded $30 \mathrm{mpy}$, and Schwenk and Divine (1993) note that wall 
Table A-1. Corrosion Data for Carbon Steel in Various Tanks and from Laboratory Tests.

\begin{tabular}{|c|c|c|c|c|c|c|c|c|c|c|c|c|c|}
\hline i.r.t. & 14., 17r & $10 \%$ & 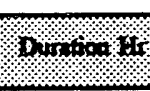 & ill. & t: 19 & $809 \%$. & $\sqrt{1}+1.19$ & 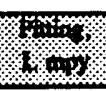 & 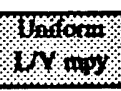 & 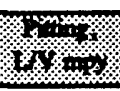 & $\frac{1}{4}$ & 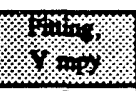 & $8=0$ \\
\hline Lab & PUREX & 1953 & 2,160 & UNK & 104 & - & 0.8 & - & - & - & 0.23 & 7 & 13 \\
\hline Lab & PUREX & 1954 & $\begin{array}{l}730 \\
2190 \\
7300\end{array}$ & 13 & 104 & None & $<1.2$ & ND & - & - & $<1.2$ & $\begin{array}{l}24 \\
8.4 \\
4.8\end{array}$ & 4 \\
\hline $\begin{array}{c}\text { PUREX } \\
101\end{array}$ & PUREX & 1956 & 3120 & & & None & 0.14 & 6.4 & $=$ & - & 0.14 & 2.0 & 1 \\
\hline $\begin{array}{l}\text { Ho Semi } \\
\text { Wortss }\end{array}$ & PUREX or REDOX & 1987 & 8,760 & UNK & UNK & - & $<1$ & -- & $<1$ & $=$ & $=$ & 1.24 & 12 \\
\hline Lab & REDOX & 1952 & 1000 & $\begin{array}{l}11 \\
12 \\
13 \\
11 \\
12 \\
13 \\
11 \\
12 \\
13\end{array}$ & $\begin{array}{c}82 \\
93 \\
\\
104 \\
(127 n\end{array}$ & ND & $\begin{array}{c}0.03 \\
0.16 \\
0.1 \\
0.1 \\
0.4 \\
0.2 \\
0.2 \\
3.1 \\
1.0\end{array}$ & ND & $\begin{array}{l}0.1 \\
0.3 \\
0.2 \\
0.3 \\
0.35 \\
0.2 \\
0.3 \\
1.6 \\
1.5\end{array}$ & ND & $\begin{array}{c}2.9 \\
2.8 \\
0.8 \\
4 \\
2 \\
2 \\
1.5 \\
4.1 \\
3.3\end{array}$ & ND & 11 \\
\hline S-104 & REDOX & 1954 & 6570 & $11-13$ & $82-127$ & None & 0.4 & 5.3 & - & - & $=$ & - & 2 \\
\hline Lab & $\mathrm{BiPO}_{4}$ & 1949 & $65-138$ & -10 & Boiling & - & $0.6(\max )$ & - & $=$ & - & - & - & 3 \\
\hline Lab & $\mathrm{BiPO}_{4}$ & 1952 & 4380 & $\begin{array}{l}6 \\
7 \\
8\end{array}$ & 80 & - & $\begin{array}{c}0.04 \\
0.01 \\
0\end{array}$ & $\begin{array}{l}32(n) \\
\text { ND } \\
\text { ND }\end{array}$ & $\begin{array}{l}0.08 \\
0.03 \\
0.01\end{array}$ & $\begin{array}{l}2.4 \\
2.8 \\
1.8\end{array}$ & $\begin{array}{l}2.4 \\
0.5 \\
0.6\end{array}$ & $\begin{array}{c}8.6(3 \mathrm{mo}) \\
5.5(3 \mathrm{mo}) \\
3(3 \mathrm{mo})\end{array}$ & 6 \\
\hline Lab & $\overline{B i P 0}$ & 1952 & -450 & "low" & 102 (boil) & $=$ & $<0.1$ & ND & - & $35(\max )$ & 1.2 & 37 (max) & 10 \\
\hline $\begin{array}{l}\text { TX-105 } \\
\text { TX-109 } \\
\text { TX-117 }\end{array}$ & $\mathrm{BiPO}_{4}$ & 1953 & 5400 & UNK & $\ldots$ & $=$ & $\begin{array}{l}\text { lost } \\
0.3 \\
\text { bost }\end{array}$ & $\begin{array}{c}\text { lost } \\
4(\max ) \\
\text { lost }\end{array}$ & - & - & $\begin{array}{c}2 \\
0.2 \\
\text { bost }\end{array}$ & $\begin{array}{c}16(37) \\
2(\max ) \\
\text { bet }\end{array}$ & 9 \\
\hline Lab & TBP & 1953 & $\begin{array}{l}730 \\
2190\end{array}$ & $\begin{array}{l}7.9 \\
7.9\end{array}$ & - & - & $\begin{array}{l}0.2 \\
-0.2\end{array}$ & $\begin{array}{l}-10 \\
-8\end{array}$ & - & $\overline{-}$ & $\begin{array}{l}-0.2 \\
-0.2\end{array}$ & $\begin{array}{l}-8 \\
-7\end{array}$ & 5 \\
\hline Survey & Nitrale & 1970 & $=$ & $<11$ & - & $\overline{Y e s}$ & $\cdots$ & - & - & - & - & - & 7 \\
\hline Lab & "Sall Cake" & 1975 & $\begin{array}{r}29-2222 \\
26-1171\end{array}$ & $\begin{array}{l}>13 \\
>13\end{array}$ & $\begin{array}{l}10 \\
34\end{array}$ & "Yes" & $\begin{array}{c}0.01-2.7 \\
0.01-16\end{array}$ & ND & - & $\overline{-}$ & $\overline{-}$ & - & 8 \\
\hline
\end{tabular}


penetration could have occurred as early as seven years since most SSTs have a liner thickness of 0.25 -in. Generally, pitting rates in the vapor phase decreased with time, but tests rarely lasted longer than three months.

During the period of 1966 to 1969 (Ondrejcin 1977), pitting of A53 and A106 carbon steel evaporator coils was discovered at Savannah River Site. At that time, the waste treatment process consisted of pumping away the supernatant liquid in the tanks and leaving the sludge behind. Then, water was added to the tanks to "slurry" the sludge so that remaining solids could be removed. Adding water significantly diluted the concentration of the soluble corrosion inhibitor chemicals in the slurry. Cooling coil leakage was observed during this processing period. Ondrejcin did a failure analysis on one coil and a laboratory corrosion study to understand the cause of the problem. At the time of the Ondrejcin report, 10 percent of the coils had leaked. The failure analysis revealed classic pits under the scale, and the pitting rate was estimated to be $150 \mathrm{mils} / \mathrm{month}(1.8 \mathrm{inches} /$ year). Laboratory studies indicated that pitting would only occur when the concentrated caustic waste was diluted by a factor of 10,000 , thereby causing the natural pitting inhibition of the nitrite to be lost through dilution. Sulfate ions contributed to lowering the effectiveness of the nitrite inhibitor. The laboratory determination of the pitting rate $(5 \mathrm{mils} / \mathrm{month})$ never successfully duplicated the rate found in the field. Ondrejcin concluded that coil failure was caused by: 1) excessive dilution of basic nitrite in the waste, 2) initiation of attack in crevices due to oxygen depletion cells, and 3) acceleration of the attack by sulfate dissolved from the sludge. The following procedure was recommended: the sludge should be slurried 1) with waste diluted by no more than one hundredfold with water, or 2) with a 500-ppm (parts per million) nitrite- $\mathrm{H}_{2} \mathrm{O}$ solution at $\mathrm{pH} 12$.

Lini (1975) reviewed the carbon steel corrosion studies carried out on Hanford waste tanks. In general, pits in the vapor phase were deeper than those found in the aqueous phase. However, the vapor phase pit growth rate decreased with time, and Lini pointed out the danger of linearly extrapolating a few months' data for life prediction. In one of the few cases involving moist solid waste, corrosion data were reported for conditions involving both high hydroxide and neutralized solid wastes. The initial testing was in polyethylene containers which cracked, and the results may have been compromised. A follow-on test series was carried out in carbon steel containers which would have become oxygen free (a serious deficiency of the second tests). Lini concluded that the pitting attack was more severe with the carbon steel exposed to the simulated moist solid waste than when exposed to the simulated liquid waste. A maximum pit depth of 12 mils was measured after one year's exposure to the highly caustic environment.

Zapp and Hobbs (1992) of Savannah River Site studied the effect of dilute caustic high-level radioactive waste slurries on pitting of ASTM A537 carbon steels. Though nitrate, sulfate, chloride, and fluoride can all act independently to induce pitting, only nitrite is a controlling anion for pitting in Savannah River Site waste solutions. Other aggressive anions (such as chloride) were at too low a level in the waste to be a problem during washing operations. Potentiodynamic pitting tests (to determine $\mathrm{E}_{\mathrm{p}}$ ) were carried out at $23,30,40,50$, and $60{ }^{\circ} \mathrm{C}$ 
in 14 different solutions that simulated various steps in the sludge washing cycle. The $\mathrm{pH}$ was adjusted between 9.5 and 10.2 to simulate equilibrium with airborne carbon dioxide. There was a concern that $\mathrm{pH}$ at the air/liquid interface would decrease in time by reacting with carbon dioxide in the air with the result the pitting inhibition of hydroxide would be lost. Nitrite at several concentrations was added to each of the solutions until the potentiodynamic tests demonstrated that pitting inhibition was achieved. Four month coupon immersion tests were then carried out at 30,50 , and $60^{\circ} \mathrm{C}$ to confirm the potentiodynamic results. A statistical analysis yielded the following equation for nitrite concentration to inhibit nitrate-induced pitting at pHs of 9.5 to 10 for the temperature range of 23 to $60^{\circ} \mathrm{C}$ :

$$
\left[\mathrm{NO}_{2}^{-}\right]=0.38 *\left[\mathrm{NO}_{3}^{-}\right] * 10^{0.041 \mathrm{~T}}
$$

Where

$$
\begin{array}{ccc}
\mathrm{T} & = & \text { Temperature, } \mathrm{C} \\
{\left[\mathrm{NO}_{2}^{-}\right],\left[\mathrm{NO}_{3}^{-}\right]} & =\text {concentration, moles/liter }
\end{array}
$$

Table A-2 shows the nitrite/nitrate ratios required to inhibit pitting as calculated from Equation 3.

Table A-2. Calculated Nitrite/Nitrate Ratios for Pitting Inhibition for $\mathrm{pH} \sim 10$.

\begin{tabular}{|c|c|}
\hline [NO, [][NO; ] & Temperature, ${ }^{\circ} \mathrm{C}$ \\
\hline 0.33 & 23 \\
\hline 1.6 & 40 \\
\hline 11.0 & 60 \\
\hline
\end{tabular}

Coupon tests were run in simulated and actual sludge supernate. The $\mathrm{pH}$ was periodically measured throughout the four-month tests. The sludge composition was $0.76 \mathrm{M}$ nitrate, $0.63 \mathrm{M}$ nitrite, $<0.0056 \mathrm{M}$ chloride, $0.5 \mathrm{M}$ free hydroxide, and other minor constituents. Over a four month period, the $\mathrm{pH}$ decreased from 13 to 11 for the concentrated supernatant. The $\mathrm{pH}$ was still decreasing when the test was terminated. For the test using a $25 \mathrm{X}$ dilution of supernate with a nitrite addition, the $\mathrm{pH}$ decreased from approximately 12 to a steady-state value of 9.5. These data show that carbon dioxide causes the $\mathrm{pH}$ to decrease with time, and the $\mathrm{pH}$ enters a regime $(\mathrm{pH} \simeq 10)$ where the carbon steel will pit. 
Elmore (1993) carried out the corrosion testing of carbon steels in simulated tank 8D-2 wash solutions for West Valley Nuclear Services. The major chemical components of the simulated waste are listed in Table A-3.

Table A-3. Target Composition of Tank 8D-2, Third-Stage Wash Simulant.

\begin{tabular}{|c|c|}
\hline Eompench & Concentration, ppn \\
\hline Nitrate & 5600 \\
\hline Nitrite & 4700 \\
\hline Sulfate & 1900 \\
\hline Chloride & 80 \\
\hline Hydroxide & $\mathrm{pH}>12$ \\
\hline
\end{tabular}

Uniform and localized corrosion testing of carbon steel tank materials was carried out at 65.6 and $87.8^{\circ} \mathrm{C}$. After six months vapor phase exposure, pits 12 mils deep were found on coupons. A few pits were observed on the fully submerged specimens; one pit was -3 mils deep.

To support sludge washing activities, Danielson and Bunnell (1994) carried out a statistically designed waste composition study of carbon steel corrosion behavior in the dilute waste environment. Incipient or shallow pits were usually observed in the vapor phase. One deep pit growing at $40 \mathrm{mpy}$ was discovered. No pitting was observed in the liquid phase.

\section{A.2 CREVICE CORROSION}

Crevices are formed whenever there is a gap between the underlying metal and an overlying structure exposed to the solution. Examples of crevice-formers include the following: bolted flanges, gaskets, weld splatter, grinding laps, salt crusts, and the meniscus region of a vapor/liquid interface. Crevice corrosion has many similarities to pitting (Claiborne et al. 1985). In particular, the growth stages are believed to be alike. Consequently, environments that result in pitting are also likely to result in crevice corrosion. In practice, the general environment is usually oxygenated while the solution within the crevice gap is depleted in oxygen. As a result, the electrochemical potential in the crevice becomes less anodic (less positive). Since the exterior and interior of the crevice are electrically connected to each other through the metal and the ionically-conducting solution, the exterior electrochemical potential polarizes the crevice anodically; that is, drives the crevice cell into a potential regime that increases the crevice corrosion rate. The local chemistry in the crevice region gradually becomes more aggressive with time and, in turn, supports an even higher corrosion rate. It is the conditions of anodic polarization and 
aggressive chemistry development that the pitting and crevice corrosion phenomena share. Consequently, the conditions leading to pitting also apply to crevice corrosion.

The Schwenk and Divine (1993) review of the historical corrosion data from 1949 to 1987 associated with Hanford does not specifically cite any crevice corrosion data.

The salt cake corrosion study of Payer et al. (1975) closely resembles a creviced environment if the salt cake forms a tight seal with the metal. No pitting (and presumably no crevice attack) was observed in that study.

Divine et al. (1985) studied the uniform, localized, and stress corrosion cracking of carbon steels A-516 and A-537 over a wide range of Hanford waste compositions and temperatures. Temperatures ranged from 25 to $180^{\circ} \mathrm{C}$ with a test duration of 4 to 12 months. Some of the test solutions contained solids. Crevice corrosion was not observed. See Section A.5 of the Appendix on uniform corrosion for more experimental details.

Zapp and Hobbs (1992) mention that crevice corrosion was often observed on the carbon steel electrode (under the gasket) after running a potentiodynamic pitting scan.

To support sludge washing activities, Danielson and Bunnell (1994) carried out a statistically designed waste composition study of carbon steel corrosion behavior in the dilute waste environment. While pitting was not observed in the liquid phase, crevice corrosion was observed in two of the 16 test solutions. These two solutions had the following composition:

$0.025 \mathrm{M}$ nitrite, $0.393 \mathrm{M}$ nitrate, $0.026 \mathrm{M}$ hydroxide

$0.10 \mathrm{M}$ nitrite, $1.00 \mathrm{M}$ nitrate, $0.10 \mathrm{M}$ hydroxide

Solution compositions supporting crevice corrosion were characterized as low in hydroxide with a nitrate to nitrite ratio $\geq 10$.

\section{A.3 STRESS CORROSION CRACKING (SCC)}

Claiborne et al. (1985) briefly reviewed SCC fundamentals and carbon steel corrosion behavior for the Basalt Waste Isolation Project. They noted that SCC is dangerous because cracks grow into the metal and greatly reduce its engineering strength. Stress corrosion cracking has two stages: incubation and propagation. For carbon steels, hydroxide and nitrates are powerful agents for driving environmentally-assisted SCC. Generally, SCC becomes more severe as the temperature and concentration of the cracking agent increase. In aqueous solutions, the electrochemical potential often plays a major role in determining the severity of SCC. If a material is prone to SCC, careful engineering design can permit the material to be used. Fracture mechanics is a modern day approach to understanding and designing structures using engineering materials of limited fracture toughness. 
Ondrejcin (1984) of Savannah River Site pioneered the study of the environmental effects of complex waste chemistry on the SCC behavior of carbon steels used in waste storage tanks. Ondrejcin recognized the complexity of the chemical interaction and used a Plackett-Burnman reduced factorial method (studied temperature + six anionic species at two levels of variation) to investigate which independent variables affected the SCC of carbon steels by using the slow strain rate technique. Test results indicated that temperature and nitrate had the most effect. Hydroxide and nitrite did not show an effect, although Ondrejcin mentions that increasing the hydroxide concentration decreases the cracking rates in nitrate solutions. Since the Plackett-Bumman approach examines first-order effects only, the lack of variable response for hydroxide and nitrite may indicate interaction between these two variables caused by higher-order effects. Next, Ondrejcin used a multivariable statistical method to create polynomial expressions relating temperature, nitrate, nitrite, and hydroxide to cracking propensity. (Cracking propensity was evaluated from slow strain rate tests from total elongation, uniform elongation, reduction in area, and ultimate tensile strength.) This final study (at three levels of each variable) demonstrated that the four variables above had a major influence on environmentally-assisted SCC. This database was used as the major predictor for unsafe/safe chemical regimes in operating Savannah River Site and Hanford Site waste tanks. The recommended chemistry limits for controlling SCC are in Table A-4. These results apply to concentrated wastes since the dilute wastes (less than $1.0 \mathrm{M}$ nitrate) were not a part of the original study.

Table A-4. Recommended Anion Limits (Ondrejcin et al. 1979 and Kirch 1984) for Safe Storage of Liquid High-Level Wastes.*

\begin{tabular}{|c|c|c|}
\hline \multirow{2}{*}{ 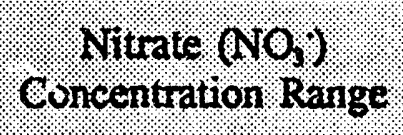 } & \multicolumn{2}{|c|}{ Mínimum Concentration } \\
\hline & $\mathrm{OH}$ & $\mathrm{OH}^{-}+\mathrm{NO}_{2}$ \\
\hline 3.0 to $5.5 \mathrm{M}$ & $0.3 \mathrm{M}$ & $1.2 \mathrm{M}$ \\
\hline 1.0 TO $3.0 \mathrm{M}$ & $0.1\left[\mathrm{NO}_{3}{ }^{-}\right]$ & $0.4\left[\mathrm{NO}_{3}{ }^{-}\right]$ \\
\hline$<1.0 \mathrm{M}$ & $0.01 \mathrm{M}(\mathrm{pH}=12)$ & \\
\hline
\end{tabular}

* Limits apply to concentrated wastes at a temperature less than boiling point, and less than $70^{\circ} \mathrm{C}$ for fresh waste solutions. The maximum NO; concentration is $5.5 \mathrm{M}$. The maximum $\mathrm{OH}^{\circ}$ concentration is $10 \mathrm{M}$ for $\mathrm{NO}_{3}=$ 1 to $5.5 \mathrm{M}$, and $5 \mathrm{M}$ for $\mathrm{NO}_{3}^{-}$less than $1 \mathrm{M}$.

The Lini (1975) review of corrosion studies at Hanford also includes some SCC studies. Lini concluded that the leaking waste tanks at Savannah River Site and Hanford Site were probably caused by SCC of the nonstress-relieved tank walls rather than pitting. Some confirmatory testing at Hanford showed that, in nitrate concentrations of 0.05 to $10 \mathrm{M}$, a temperature greater than $60^{\circ} \mathrm{C}$ and a pH of 6.6 to 9.8 would generally result in the SCC of pre-cracked C-ring specimens. A pH of 11 to 12 generally inhibited SCC. Lowering the 
temperature was also found to be beneficial. No SCC was observed under salt cake conditions, because the salt was at a high hydroxide level, which would act as an inhibitor for SCC.

Payer et al. (1975) studied the corrosivity of synthetic salt cake on A283 carbon steel at 50 and $93{ }^{\circ} \mathrm{C}$. The slow strain rate method was used to study SCC propensity. A variety of salt cake compositions were studied, most were 5.7 and $10 \mathrm{M}$ hydroxide levels with high levels of nitrate and nitrite (nitrate/nitrite ratio $>1$ ). Stress corrosion cracking was often observed even when the chemistry fulfilled the Ondrejcin recommendations for safe storage of the concentrated waste. A significant observation was that when the specimen was electrochemically polarized 50 to $150 \mathrm{mV}$ anodic to the open circuit potential, SCC propensity increased even in systems which showed no SCC at the open circuit potential. Ionizing radiation usually acts to polarize the open circuit potential anodically, and this experimental feature is very difficult to duplicate in a laboratory test. The results hint that SCC may be more likely under ionizing radiation conditions, but no studies have been carried out in Hanford waste environments to confirm this.

Beavers et al. (1985) wrote a review paper discussing the effects of hydroxide and nitrates on the SCC behavior of carbon steels. The review indicates there is a mass of conflicting SCC data in hydroxide solutions. In one section, the reviewers quote data indicating that SCC does not occur below $90^{\circ} \mathrm{C}$, but a later section reports that SCC has been observed at lower temperatures. Immunity to SCC has been reported in hydroxide concentrations below 5 percent. However, Fessler (1976) has observed the occurrence of SCC in pipeline steels in $60^{\circ} \mathrm{C}$ carbonate/bicarbonate solutions at a $\mathrm{pH}$ nearly equal to 10 (hydroxide concentrations orders of magnitude lower than found in 5 percent $\mathrm{NaOH}$ ). Beavers et al. (1985) report that small amounts of additives to caustic solutions (silicates, sulfates, nitrates and permanganates) can stimulate cracking by their effect on the corrosion potential (SCC in hydroxide is an anodically assisted phenomenon) while higher levels of polarization can inhibit cracking. Very little fracture mechanics slow crack growth data are reported except for a value of $\mathrm{K}_{\mathrm{ISCC}} \leq 18 \mathrm{MPa} \sqrt{\mathrm{m}}$ in 33 percent $\mathrm{NaOH}$ at $92{ }^{\circ} \mathrm{C}$. Donovan (1977) conducted bolt-loaded wedge-open-loaded tests of a Savannah River Site waste tank steel (A 285 grade B) in simulated waste solutions that contained $5 \mathrm{M} \mathrm{NaNO}_{3}$ and various amounts of $\mathrm{NO}_{2}^{-}$and $\mathrm{OH}^{-}$. He obtained the threshold stress intensity $\left(\mathrm{K}_{\mathrm{Iscc}}\right)$ values from about $27 \mathrm{MPa} \sqrt{\mathrm{m}}\left(0.3 \mathrm{M} \mathrm{OH}^{-}\right.$and zero $\left.\mathrm{NO}_{2}{ }^{\circ}\right)$ to as high as $35 \mathrm{MPa} \sqrt{\mathrm{m}}\left(0.3 \mathrm{M}\right.$ each of $\mathrm{OH}^{-}$and $\left.\mathrm{NO}_{2}{ }^{-}\right)$. Larger amounts of $\mathrm{NO}_{2}^{-}$appeared to increase the threshold stress intensity $\left(\mathrm{K}_{\mathrm{lscc}}\right)$ but were associated only with solutions that contained no $\mathrm{OH}^{\text {. }}$

Beavers et al. (1985) indicate that nitrates are a more potent cracking agent than hydroxide because nitrate-promoted SCC takes place over a much wider electrochemical potential range than hydroxide-promoted SCC. Nitrate cracking has traditionally been associated with concentrated solutions (greater than $1 \mathrm{~N}$ ) near the boiling point. The review reports smooth tensile bar testing at a constant strain in $1 \mathrm{M}$ nitrate solution in which little or no SCC was observed to support this contention. However, using the more sensitive slow strain rate technique for detecting SCC, cracking was observed in $0.01 \mathrm{M} \mathrm{KNO}_{3}$ solutions at boiling temperatures, and cracking propensity increased with temperature. Chloride and bromide 
additions generally retarded the cracking process, while fluoride additions had no effect. Oxidizing species accelerated cracking, while reducing species slowed the cracking process. Little mention was made about the effect of $\mathrm{pH}$ other than to say that the minimum in cracking propensity is at $\mathrm{pH} 4$. No threshold stress intensity $\left(\mathrm{K}_{\mathrm{lscd}}\right)$ fracture mechanics data were reported. The crack growth rates were high (1E-5 mm/s in boiling $0.01 \mathrm{M} \mathrm{KNO}$ ).

Divine et al. (1985) studied the uniform corrosion, localized, and SCC of A-516 and A-537 carbon steels over a wide range of Hanford waste compositions and temperatures. Stress corrosion cracking (using U-bends) was rarely observed and only in two different operating states: low temperature (less than $100^{\circ} \mathrm{C}$ ), low hydroxide conceitration; and high temperature $\left(140\right.$ or $\left.180^{\circ} \mathrm{C}\right)$, high hydroxide concentration. The low temperature chemistry conditions for SCC are listed in Table A-5.

Table A-5. Compositions for Low Temperature SCC.

\begin{tabular}{|c|c|c|}
\hline Hifroxido & Mitraro & Nitrite. \\
\hline $0.2 \mathrm{M}$ & $2.0 \mathrm{M}$ & $0.01 \mathrm{M}$ \\
\hline 0.2 & 5.0 & 0.01 \\
\hline 0.2 & 5.0 & 0.1 \\
\hline
\end{tabular}

To support sludge washing activities, Danielson and Bunnell (1994) carried out a statistically designed waste composition study of carbon steel corrosion behavior in the dilute waste environment. The range of compositions was designed to connect to the lower end of Ondrejcin's database (less than $0.1 \mathrm{M}$ nitrate) and extend the compositional range into the $0.01 \mathrm{M}$ state for hydroxide, nitrate, and nitrite. Stress corrosion cracking was determined by the slow strain method in Solutions \#1 and $\# 2$ which had the following composition:

$0.025 \mathrm{M}$ nitrite, $0.393 \mathrm{M}$ nitrate, $0.026 \mathrm{M}$ hydroxide $(\# 1)$

$0.10 \mathrm{M}$ nitrite, $1.00 \mathrm{M}$ nitrate, $0.10 \mathrm{M}$ hydroxide ( $\$ 2)$

These two solutions also supported crevice corrosion and were characterized as low in hydroxide with a nitrate to nitrite ratio $\geq 10$. Ominously, solution $\# 1$ appears to be within the recommended limits of Table A-4 for safe operating conditions. On the positive side, there is a wide range of solution compositions in the dilute range that are immune to SCC.

\section{A.4 HYDROGEN EMBRITTLEMENT}

Hydrogen embrittlement is a form of environmentally-assisted failure that results from the combined action of hydrogen and residual or applied stress. Hydrogen damage can manifest itself in four ways: loss of tensile ductility (often observed during the slow application of strain), formation of blisters or voids (hydrogen blistering), hydride formation, and hydrogen 
stress cracking ${ }^{1}$. Collectively these terms are referred to as hydrogen embrittlement (HE). Of these four mechanisms, three are applicable to SSTs; loss of ductility, formation of blisters, and hydrogen stress cracking.

\section{A.4.1 Three Forms of Hydrogen Damage in Steels}

A.4.1.1 Lass of Tensile Ductility. Slow strain-rate embrittlement is the classic type of HE. Some investigators include delayed failure or static fatigue in this category. Because this aspect of static loading is clearly demonstrated in static load tests of notched specimens, it is in the category of hydrogen stress cracking. Nelson (1983) also refers to this form of HE as internal reversible HE. For the embrittlement to be fully reversible, it must occur without the hydrogen undergoing any chemical reaction after it has been absorbed in the lattice. Internal reversible HE can occur after a very small average concentration of hydrogen has been absorbed from the environment. For steels, embrittlement is usually most severe at or near room temperature during slow strain-rate testing. The time-dependent nature of embrittlement suggests that diffusion of hydrogen within the lattice controls this type of embrittlement. The degree of embrittlement normally increases with decreasing strain-rate. Embrittlement can occur for a hydrogen content as low as one atom in 100,000 (Cotterill 1961).

The embrittlement is reversible in carbon steels (i.e., the ductility can be restored) by decreasing the applied stress and aging at room temperature, provided microscopic cracks have not yet been formed. Embrittlement can result from electroplating, melting, or pickling (chemical dissolution of outer layers of steel). More recently, the embrittling effects of many SCC processes have been attributed to corrosion-produced hydrogen. One example of the effect of increasing hydrogen concentration in decreasing ductility (percent elongation) in a normalized steel is shown in Figure A-1 (Cotterill 1961).

A.4.1.2 Formation of Blisters. This type of embrittlement is distinct from the slow strainrate type noted in Section A.4.1.1. Once hydrogen is absorbed, it may react near the surfaces or diffuse significant distances before it reacts. Hydrogen can react with itself, with the matrix, or with a foreign element (such as normal impurities, internal defects, or nonmetallic inclusions) in the matrix. This phenomenon is normally found in low-strength steels. Specifically, atomic hydrogen can react with itself to form molecular or gaseous hydrogen $\left(\mathrm{H}+\mathrm{H}=\mathrm{H}_{2}\right)$. This problem is frequently encountered after steel processing and welding; it has been termed fisheyes, flaking, and shatter cracks; the latter two are generally associated with forgings and castings. The pressure of molecular hydrogen can attain such high values that local plastic deformation of the alloy occurs, forming a blister that often ruptures. Hydrogen sulfide has also been known to form in gas pipeline steels that contain sour gas (Bieber 1982).

\footnotetext{
${ }^{1}$ This particular breakdown was used because of its simplicity; other ways of partitioning this phenomena can be found in various review articles and other dominant hydrogen damage literature.
} 
Figure A-1. The Variation of Elongation with Hydrogen Content for a Normalized Mild Steel Tested at a Slow Strain-Rate at Room Temperature.

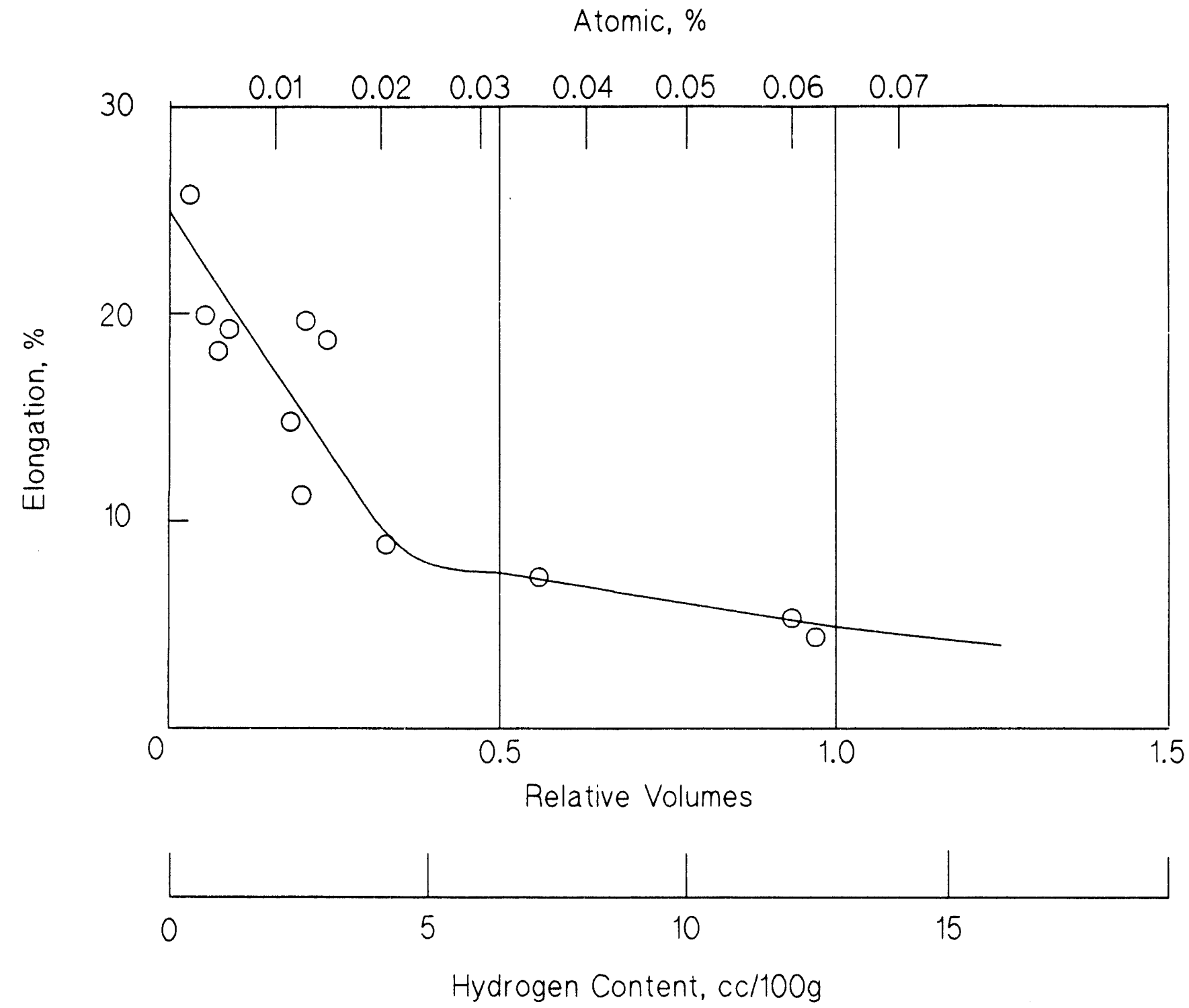


Conditions that lead to blistering include the following: electroplating, acid pickling, or electrolytic pickling with current reversal (cathodic hydrogen), and high pressure hydrogen on the process side (Warren 1986). Blistering can result from corrosion of the steel on the process side or on the atmospheric side with atomic hydrogen charged into the steel as a by product of the following reaction:

$$
\begin{array}{ll}
\mathrm{Fe}^{\circ}=\mathrm{Fe}^{++}+ & 2 \mathrm{e}^{-} \\
2 \mathrm{H}^{+}+2 \mathrm{e}^{-}= & \begin{array}{l}
2 \mathrm{H} \text { (into steel) instead of gas }\left(\mathrm{H}^{2}\right) \\
\text { evolution. }
\end{array}
\end{array}
$$

Warren (1986) claims that blistering may occur from corrosion rates as low as $2 \mathrm{mpy}$ and over long periods of time (10 to 12 years).

A.4.1.3 Hydrogen Stress Cracking. Hydrogen stress cracking (HSC), often referred to as hydrogen-induced cracking or static fatigue, is characterized by the brittle fracture of a normally ductile alloy under sustained load in the presence of hydrogen. Frequently, a fracture occurs at sustained load below the yield strength of the steel. This cracking mechanism depends on the, hydrogen fugacity (or concentration in the steel), the strength level of the steel including heat treatment/microstructure, applied stress, and temperature.

For many steels, a threshold stress exists below which HSC does not occur. This threshold is a function of the strength level of the steel and the specific hydrogen-bearing environment. Therefore, the threshold stress or threshold stress intensity $\left(\mathrm{K}_{\mathrm{th}}\right)$ for HSC is not considered a material property. Generally, the threshold stress intensity decreases as the yield stress and ultimate tensile stress of steels increase. Hydrogen stress cracking is associated with absorption of hydrogen and a delayed time to failure (incubation time) during which the hydrogen is believed to diffuse into regions of high triaxial stress. An example of the effect of decreasing metal strength on the increase in $\mathrm{K}_{\mathrm{t}}$ for HSC is shown in Figure A-2

(Nelson 1983). Note how the $\mathrm{K}_{\mathrm{t}}$ value (knee in curve) increases desirably as material yield stress and ultimate tensile stress decrease.

Hydrogen Trapping: Another issue involving diffusion is hydrogen trapping. Diffusion studies in some steels have shown that an initial retardation in diffusion rate (lag time) can occur around room temperature before a steady-state diffusivity (D) occurs (Hirth 1980). This lag time, which is also characterized by a dec-ease in $D$, is generally considered to be related to the filling of traps by hydrogen. Hydrogen trapping according to Craig (Metals Handbook 1987) may be due to the binding of hydrogen to impurities, metallurgical defects, or microstructural constituents. Craig considers short-term trapping as reversible and a long residence time and a high binding energy as irreversible. McCright (1977) indicates that hydrogen-trapping is apparently more of a problem for higher strength steels. The concentration of trapped-hydrogen increases with yield stress. Since SST steels are low strength, trapping is assumed an insignificant rate-controlling factor.

Stress Corrosion Cracking: An example of further confusion in describing HE is its apparent relation to stress corrosion cracking (SCC). It is particularly obvious when comparing crack 
Figure A-2. Hydrogen-induced Slow Crack Growth as a Function of Applied Stress Intensity Factor in a Martensitic (4130) Steel Tempered to Various Strength Levels $\mathrm{P}_{\mathrm{H} 2}=77.3 \mathrm{kNm}^{-2}$.

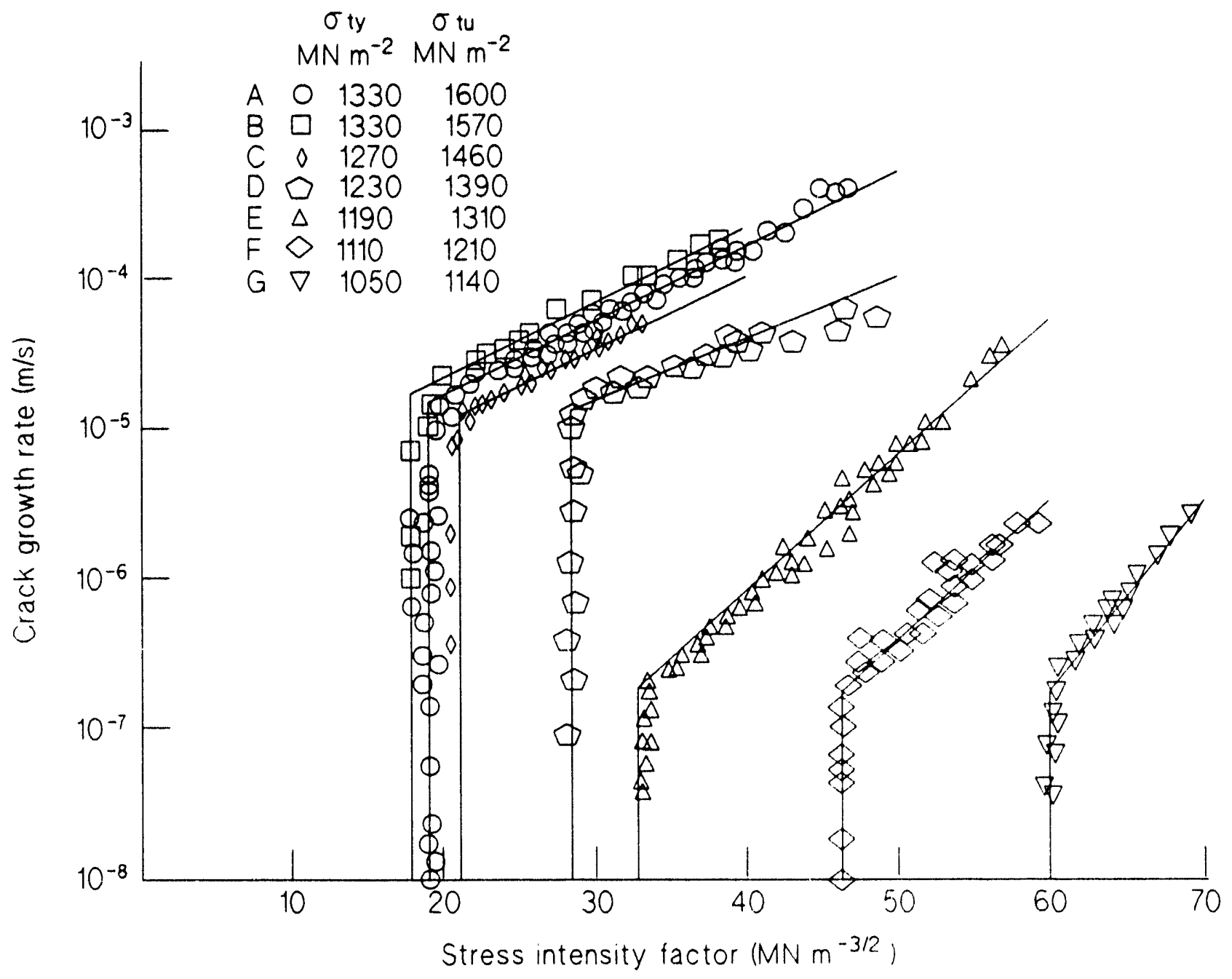


velocity (da/dt) versus stress-intensity factor $(K)$ curves for both failure mechanisms (see Figure A-3). Both curves are the same, and both display a threshold value $\left(\mathrm{K}_{\mathrm{t}}\right.$ or $\left.\mathrm{K}_{\mathrm{LSCC}}\right)$ below which no significant crack propagation occurs. Both can show characteristic stair-step Stage I, II and III growth. As metal strength decreases, $\mathrm{K}_{\mathrm{t}}$ (and $\mathrm{K}_{\mathrm{IscC}}$ ) increases, and Stage II slow crack growth rate generally decreases making low strength alloys less susceptible to HE and SCC under conditions of static load.

\section{A.4.2 Hydrogen Generation Processes}

For HE to occur, there must be a source of hydrogen gas.

Electrochemical processes, such as electrodeposition, pickling, corrosion and cathodic protection are particularly potent hydrogen sources. Certain elements in the solution or in steel grain boundaries can pro.note hydrogen entrance into steel, through the formation of hydrides with those elements. In addition, other non-hydriding species such as cyanide ion $\left(\mathrm{CN}^{-}\right)$and sulfide $\left(\mathrm{S}^{2-}\right)$ can increase hydrogen entry into the steel. These electrochemical effects, along with environmental variables and metallurgical structure, have been subdivided into five categories by McCright (1977), under the term Hydrogen Absorption Reaction (HAR).

Hydrogen Absorption Reaction: According to McCright the HAR rate expression can be written in the form: rate $=$ constant $\mathbf{x}$ (concentration term). If the source of hydrogen is the monatomic gas that adsorbs to the metal surface, the rate of entry is:

$$
r=v \theta M_{1} e^{(-\Delta H * / R T)}
$$

Where

$$
\begin{array}{lll}
\nu & = & \text { Frequency factor } \\
\mathrm{M}_{\mathbf{\Delta}} & = & \text { Number of metal sites available for adsorption } \\
\theta & = & \text { Fraction of bare metal sites } \\
\Delta \mathrm{H}^{*} & = & \text { Activation energy for the absorption step }
\end{array}
$$

McCright views the extent of HAR to be controlled by the following: the potential of the metal (and hence the current density); the $\mathrm{pH}$ and composition of the solution; the presence of certain species (promoters) that catalytically favor hydrogen absorption; temperature; and the presence or absence of stress.

\section{Electrochemical Potential of the Metal}

Although McCright claims that the electrochemical potential profoundly influences the HAR through the pre-exponential and the exponential parts, there is apparently no quantitatively 
Figure A-3. Typical Forms of Crack Growth Rate (da/dt) Versus Stress-Intensity Factor Curves for (a) Hydrogen Stress

Cracking and (b) Stress Corrosion Cracking.

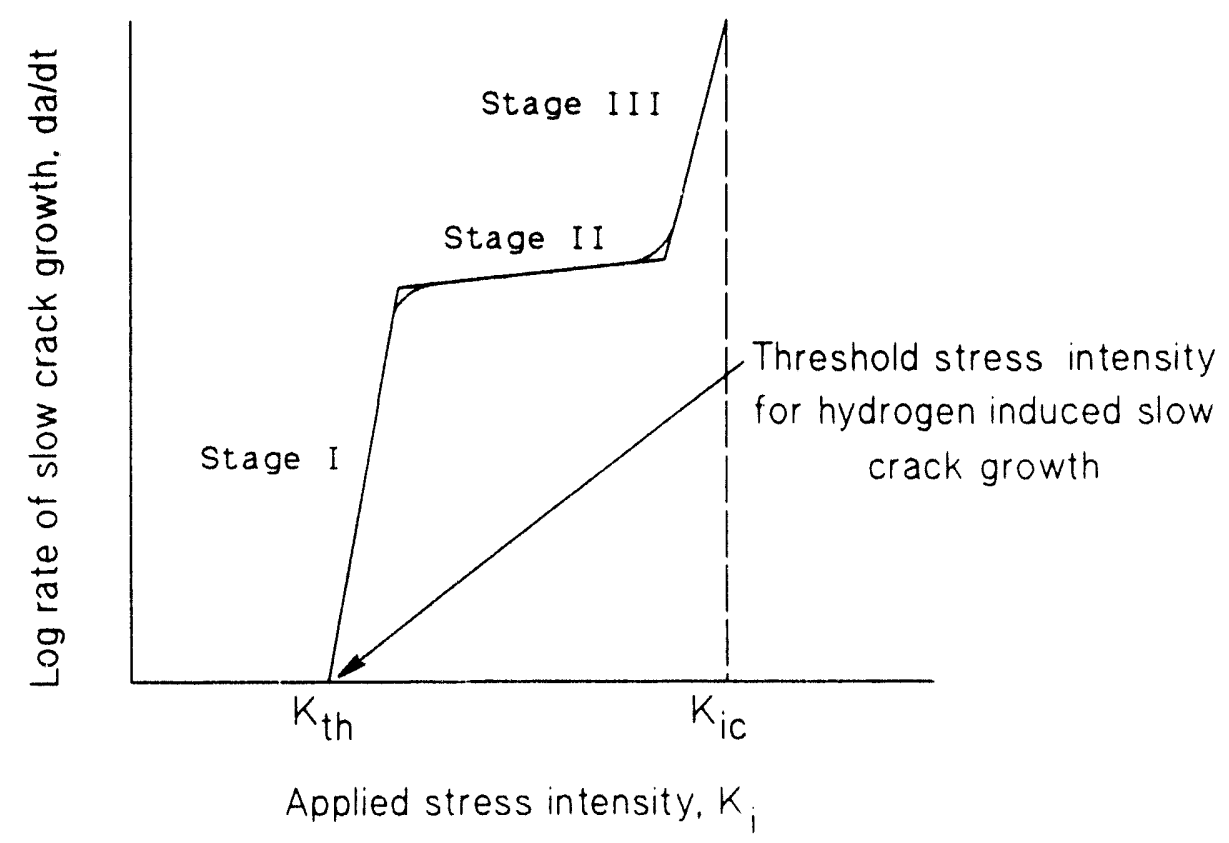

a) Hydrogen stress cracking

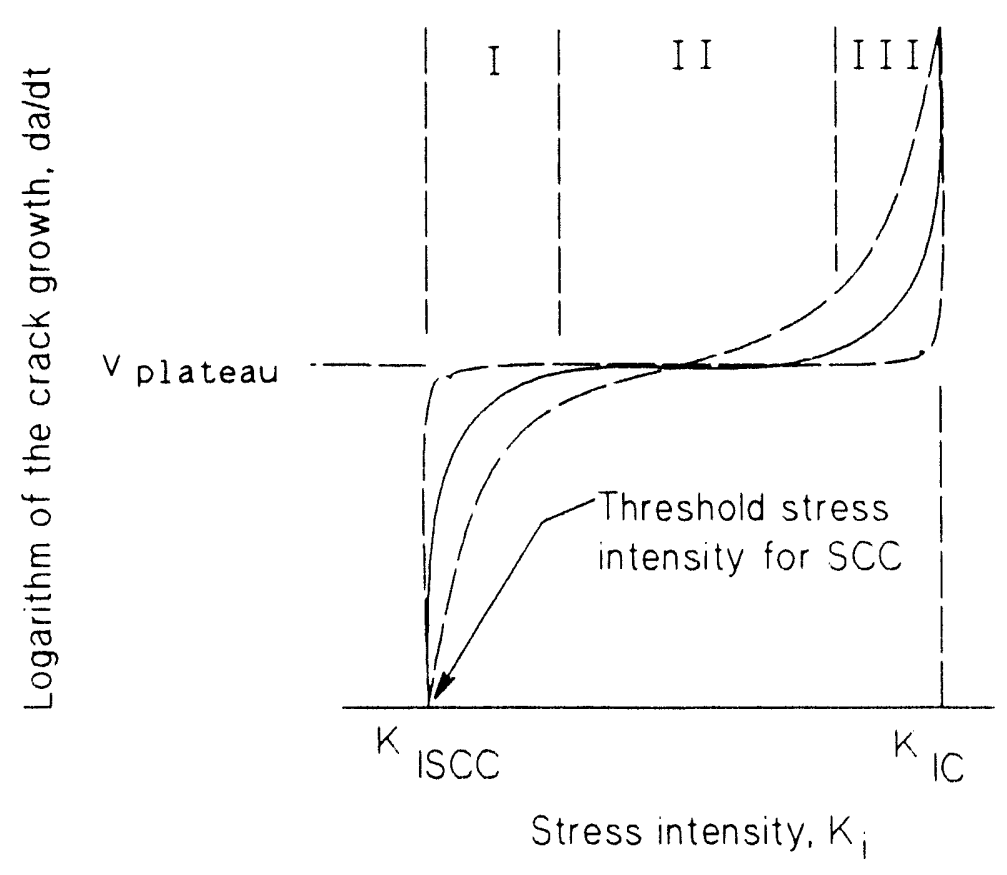

b) Stress corrosion cracking 
predictable way to evaluate the role of potential. From a thermodynamic point of view, the hydrogen fugacity at the metal/solution interface establishes the concentration of dissolved hydrogen inside the metal. The potency of the electrochemical generation of hydrogen is demonstrated through hydrogen permeation experiment (Bockris et. al. 1981). On Armco iron in $0.1 \mathrm{~N} \mathrm{H}_{2} \mathrm{SO}_{4}$, a cathodic polarization of $250 \mathrm{mV}$ relative to the standard hydrogen electrode creates an equivalent hydrogen partial pressure at the metal/solution interface of 100 atmospheres. Unfortunately, permeation data are very rare in the literature; no data could be found in environment relevant to SSTs.

\section{Solution pH and Composition}

At the corrosion potential, the rate of hydrogen entry increases with acidity (decreasing $\mathrm{pH}$ ) and is affected by the composition of the solution (Metals Handbook 1987 and Smialowski 1972). In alkaline solutions, a cathodic potential must be applied to effect hydrogen entry, since the corrosion potential in these solutions is above the reversible potential for hydrogen evolution. In general, the lower the $\mathrm{pH}$, the higher the entry rate will be.

\section{Promoter Species}

The terms cathode poison or cathode promoter are applied to species that promote hydrogen entry into the steel. Smialowski (1972) found that certain elements and compounds of group $\mathrm{Va}$ and VIa of the periodic system enable hydrogen to enter metals. These include nitrogen $(\mathrm{N})$, phosphorus $(\mathrm{P})$, arsenic (As), americium (Sb) and bismuth (Bi), and oxygen $(\mathrm{O})$, sulfur $(\mathrm{S})$, selenium (Se), and tellurium (Te). Smialowski also claims that the promoting effect occurs at extremely low concentrations, on the order of $10^{-6}$ to $10^{-8}$ moles/liter, depending on the element. These species also include the cyanide ion $\left(\mathrm{CN}^{-}\right)^{2}$ in alkaline solution and the aromatic hydrocarbon naphthalene. In some circumstances, salts of metals such as mercury $(\mathrm{Hg})$, tin $(\mathrm{Sn})$ and lead $(\mathrm{Pb})$ have also been reported to enable hydrogen entry (McCright 1977).

In addition, a mechanism has been presented (Metals Handbook 1987) in which grain boundary impurities (group Va and VIa elements) act as hydrogen recombinant poisons and enhance hydrogen uptake of cathodic hydrogen.

The cyanide ion is known to destroy the protective film on steel and to convert it to soluble ferrocyanide $\mathrm{Fe}(\mathrm{CN})_{6}{ }^{-4}$ complexes (Metals Handbook 1987). The handbook also indicates that aqueous hydrogen sulfide solutions with high $\mathrm{pH}$ values cause hydrogen damage if cyanide ions $\left(\mathrm{CN}^{-}\right)$are present; and it claims that it has been shown experimentally that steel corrosion in aqueous ammonia/sulfide environments with $\mathrm{pH}$ values above 8 is always

\footnotetext{
${ }^{2}$ In a brief review of the literature, no information was found concerning the possibility of ferrocyanide $\left[\mathrm{Fe}(\mathrm{CN})_{6}^{-4}\right]$ producing $\mathrm{HE}$ under cathodic conditions.
} 
accompanied by hydrogen damage. Bockris et al. (1965) found an increase in hydrogen permeation rate for hydroxide solutions containing cyanide. No data were found indicating that $\mathrm{Fe}(\mathrm{CN})_{6}{ }^{-4}$ is a hydrogen recombinant poison.

\section{Temperature}

The effect of temperature has been explored with respect to acidic solutions (McCright 1977). The hydrogen absorbed from acidic pickling solutions $\left(\mathrm{H}_{2} \mathrm{SO}_{4}, \mathrm{HCL}\right.$, and $\mathrm{H}_{3} \mathrm{PO}_{4}$ ) increased with increasing temperature and with the square root of the exposure time.

\section{Stress}

The effect of stress was investigated by Beck et al. (1966). They argued that the effect of tensile strain increases the concentration of absorbed hydrogen because of dilation of the interstitial lattice sites where hydrogen lodges. The diffusivity of hydrogen did not change from an unstressed to the stressed condition so that the increase in permeability caused an increase in solubility.

\section{A.4.3 Hydrogen Embrittlement Characteristics of Steels}

The physical effects of hydrogen on the mechanical properties of iron and steel are important for establishing how HE forms may be manifested. According to Cotterill (1961), they are as follows:

1. Hydrogen has no significant effect on elastic properties.

2. Hardness remains unaffected by hydrogen in the range $0.10 \mathrm{~cm}^{3} / 100 \mathrm{~g}$ although the ultimate tensile strength is decreased.

3. Fracture stress is lowered in proportion to the hydrogen concentration.

4. Both the ductility (plasticity) parameters, elongation and reduction of area, are reduced in proportion to the hydrogen content up to about $5 \mathrm{~cm}^{3} / 100 \mathrm{~g}$ (approximately 0.025 atomic percent). Above this figure, the ductility has a constant, low value.

5. Hydrogen embrittlement is reduced as the rate of strain is increased, the limiting case being the impact test on which hydrogen has virtually no effect.

6. The embrittlement effect occurs in the temperature range -100 to $+100{ }^{\circ} \mathrm{C}$, the maximum effect being near room temperature. 
7. There are no instances in the literature of HE during the compression testing of steels. It would appear that tensile stresses are required to cause this embrittlement ${ }^{3}$.

8. The presence of hydrogen in steel changes the fracture type from a typically ductile metal to a typically brittle material (usually by cleavage). Hirth (1980) showed that for a given fractographic failure mode, hydrogen can reduce ductility while maintaining the same mode.

9. The phenomenon cif HE depends upon the treatment to which any given sample has been subjected. Steels are particularly susceptible if they are in a hardened or a spherodized condition. Cold working also increases the likelihood of HE.

10. Under static loading conditions, the presence of hydrogen causes premature brittle fracture in high strength alloy steels. This phenomenon is often referred to as delayed failure or static fatigue.

11. The presence of hydrogen in steel does not affect the metal in the unstrained state. The removal of hydrogen from solid steel prior to straining ensures full ductility. It would appear that $\mathrm{HE}$ requires the presence of diffusible hydrogen during the course of straining.

12. If hydrogen concentration varies throughout a specimen, the hydrogen-rich areas will be those which are least ductile, and their premature fracture will result in an overall ductility of the specimen. This is typical of the locally enriched areas rather than the average hydrogen content.

\section{A.4.4 Hydrogen Embrittlement Mechanisms and Failure Modes Applied to SSTs}

Any attempt to define and identify waste tanks that may have been subject to HE has some difficulties. First, there is no consensus regarding the mechanism(s) of HE, and there is disagreement regarding the site of embrittlement and the atomic mechanisms of crack growth. According to Lynch (1984), this situation arose for the following reasons:

1. Hydrogen atoms are very mobile.

2. Critical embrittlement events occur at an atomic scale at or near inaccessible crack tips.

3. Hydrogen embrittlement is accompanied by several causes of failure (e.g., brittle intergranular fracture, quasi-cleavage, and ductile rupture) while other embrittlement mechanisms are generally more fracture-specific.

\footnotetext{
${ }^{3}$ Because SCC and liquid metal embrittlement behave similarly, some investigators believe that all three failure modes have a common basis (Lynch 1984, Stoloff 1984, Tetelman and Kunz 1977).
} 
Hirth (1980) extends the causes of failure to include all microstructural fracture causes and adds ductile tearing and transgranular cleavage to Lynch's list. Hirth also claims that hydrogen tends to degrade fracture properties without changing the microstructural causes of fracture. Thus, fractographic assessment of a hydrogen-exposed metal is, by itself, insufficient to tell if $\mathrm{HE}$ has occurred.

Another factor causing concern about HE in SSTs is that steel with ultimate tensile strength values less than $100 \mathrm{ksi}$ is no longer considered immune to HE (Hirth 1980). This effect was discovered when a normalized 0.22 percent $C$ steel and an ASTM A 301 steel were exposed to hydrogen pressures of about 700 to 1,500 psi. All Hanford SSTs and DSTs are made of steel with tensile strength levels less than $100 \mathrm{ksi}$; recent DST steels (ASTM A 537 Class 1) are typically in a normalized condition and contain carbon as high as 0.24 percent. They are, however, not exposed to a hydrogen pressure greater than that associated with a given waste tank's hydrostatic head unless there is an electrochemical source of hydrogen. Bernstein et. al. (1976) claim that designers can no longer assume that steels with strengths below $100 \mathrm{ksi}$ will avoid HE; however, they do not clarify the level of hydrogen pressures necessary to produce this condition.

In the brief review of crack growth literature, Tuttle and Kochera (1975) described the variation of $K_{b}$ as a function of yield strength. The material, "controlled yield 90 ," has been used by Shell Oil Co. for hydrogen sulfide cracking resistance. This material has a composition close to that of AISI 4130-4135, a quenched and tempered steel (namely 0.30 to 0.35 percent $\mathrm{C}$ ). Extrapolation to an ultimate tensile strength level of $80 \mathrm{ksi}$ (the lowest practical level) suggests that the hydrogen sulfide $K_{\text {th }}$ value would be about $50 \mathrm{ksi} / \mathrm{in}$. Donovan (1977) conducted nitrate SCC tests on a waste tank steel (ASTM A 285 Grade B, 50-70 ksi ultimate tensile strength). The lowest threshold $\mathrm{K}_{\mathrm{IsCC}}$ level found was $24.5 \mathrm{ksi}$ in. The similarity of slow crack growth curves due to HE and SCC suggest that Hanford SST steels could, under some conditions, be sensitive to hydrogen stress cracking, but it is speculated to require higher K-levels than required by SCC-conditions.

\section{A.4.5 Sources of Hydrogen}

There are apparently three sources of hydrogen in a given SST: radiolytic, chemical, and electrochemical. Volumetrically the largest amount of hydrogen is produced by the combination of radiolysis and chemical reactions. Electrochemical generation by corrosion can produce the highest hydrogen pressures and can be the most dangerous. Fortunately, many of the tank regions are oxygenated, and oxygen reduction will take place in preference to hydrogen evolution.

Uniform corrosion is expected to be low under most conditions in SSTs. Some uniform corrosion could occur in stabilized SSTs if fluid concentrations exceeded the bounds used for salt cake corrosion tests (Payer et al. 1975). Thus, only limited amounts of hydrogen are expected to be produced by this corrosion mechanism. Pitting corrosion, which is more likely, gencrally involves a much lesser volume of metal than uniform corrosion; thus pitting 
corrosion is also not expected to produce a significant amount of hydrogen. Stress corrosion cracking, which can be driven by anodic corrosion, can produce substantial amounts of hydrogen; but it involves even lesser amounts of interacting metal compared to pitting corrosion. Thus, SCC is not expected to drive any significant amount of hydrogen into the surrounding metal matrix.

\section{A.4.6 Detailed Discussion of Factors that Could Affect Hydrogen Damage in SSTs}

This section includes a detailed discussion of factors that could lead to hydrogen damage in the vapor region, the waterline region, and the tank bottoms.

A.4.6.1 Hydrogen Embrittlement (Vapor Region). No hydrogen degradation processes are expected to have occurred in the SST vapor phase regions (see Section 2.1.3). This claim is based on the following known conditions and assumptions:

1. It is assumed that the above-liquid (above-waste) line concrete backing structure has maintained its original shape and has not produced any additional loading to the vapor-exposed portion of the liner. This means that no slow-strain-rate embrittlement or loss-of-ductility condition would exist in a given liner. Low magnification photographs taken in SST interiors indicate that no significant liner shape changes have occurred.

2. Residual stresses from the original welding are expected to exist but are probably not significant for the following reasons:

a. If SCC did occur in the vapor space region early in the life of the tank, then the highly local weldment residual stresses and the tendency for hydrogen stress cracking will be reduced.

b. If SCC ${ }^{4}$ did not occur and the welding residual stresses remain unchanged, then some potential remains for producing hydrogen stress cracking. In either case, any slow crack growth (by either SCC or HE) would reduce those residual stress fields, thereby attenuating any further cracking.

3. The hydrogen partial pressure in the vapor phase is low thus reducing the tendency for hydrogen to enter the metal.

\footnotetext{
${ }^{4}$ Some investigators believe that SCC of steel in alkaline media is due mainly to HE (Mahidhara 1992).
} 
4. Vapor space temperatures have been and are generally low (less than $100^{\circ} \mathrm{C}$ ). Therefore, no elevated temperature (e.g., no molecular hydrogen or methane produced in the microstructure at 200 to $400{ }^{\circ} \mathrm{C}$ ) hydrogen damage would be expected.

5. Vapor space hydrogen sulfide $\left(\mathrm{H}_{2} \mathrm{~S}\right)$ concentrations are believed to be small, thereby negating any lower temperature $\mathrm{H}_{2} \mathrm{~S}$ cracking.

6. Electrochemical (electroplating) reactions that can generate hydrogen are not expected to occur in the vapor-exposed liner since this region is oxygenated. The vapor-space contains oxygen which, when dissolved in any liner condensate, will tend to decrease any tendency for HE (Metals Handbook, 1987).

7. Almost 50 years have passed since the tanks were welded and when hydrogen could have been introduced. This is an adequate time for hydrogen to diffuse and escape from the liner metal.

8. The liner has a relatively low yield strength and ultimate tensile strength. Although this does not eliminate the concern for HE, it does decrease its potential.

Based on these assumptions and conditions, no HE or hydrogen damage is expected to have occurred in the vapor phase region of SST liners. Ultimately, interior inspection of SSTs and removal of potentially cracked regions for metallurgical and hydrogen analysis would be beneficial.

A.4.6.2 Hydrogen Embrittlement (Vapor-Liquid and Vapor-Liquid-Solid Interface). As with the vapor region, the potential for hydrogen damage in the vapor-liquid and vaporliquid-solid regions is expected to be low and is unlikely to occur. This is based on the following known conditions and assumptions.

1. It is assumed that the concrete backing to the liner has maintained its integrity, and that no significant changes have occurred in the geometry of the metal liner-concrete interface. A corrosion product buildup between the liner and the concrete backing, or loss of a significant amount of cement-sand from the concrete aggregate could induce more stresses in the liner. A corrosion product buildup could cause radial forces on the liner resulting in tensile bending stresses on the waste side of the liner.

Significant losses of cement-sand due to leaking waste liquid could attack the local cement-sand portion of the aggregate to be washed to lower levels producing some increase in hydraulic-induced stresses in the liner. Low magnification in-tank photographs indicate that no significant damage of this type has occurred in areas adjacent to the waterline region. 
2. The welding residual stresses are likely to have been attenuated. Stress corrosion cracking probably occurred early in the life of most or all SSTs. This, along with the possible presence of dissolved oxygen in the vapor-liquid region, would decrease the potential for any hydrogen damage. Furthermore, while some SST wastes contain a poison (e.g., arsenic), its possible effect would be reduced, because no significant potential differences are expected to exist in the upper regions of the waste (Bickford et. al. 1986). These conditions, coupled with the very low hydrogen partial pressure, general lack of $\mathrm{H}_{2} \mathrm{~S}$, and relatively low temperatures indicate that no significant hydrogen damage processes exist.

3. This interface is oxygenated, and any corrosion reactions will result in the reduction of oxygen rather than hydrogen generation. Consequently the low source of oxygen makes HE unlikely.

A.4.6.3 Hydrogen Embrittlement (Liquid Region and Liquid-Solid). It is assumed that no significant corrosion-induced products or washed-out cement-sand regions exist which could increase local liner stresses. Thus, no loss-of-ductility conditions are expected to exist.

The oxygen concentration is expected to be very low below the mensicus region for the following reasons: the tanks are not stirred, corrosion and other reactions consume oxygen, and the diffusive transport of oxygen across the mensicus is very slow. Consequently, corrosion reactions will evolve hydrogen rather than react with the dissolved oxygen. If the carbon steel remains passive (and most caustic environments result in this condition), hydrogen generation rates will remain very low. If the waste is stratified, and the caustic concentrations differ greatly between strata, then the carbon steel in the region of lower caustic concentration will be cathodically polarized and could generate hydrogen. But, again, the carbon steel in the high caustic stratum is passive, and the driving force for hydrogen evolution should be low. Consequently, if the pressure of hydrogen is low, the propensity for $\mathrm{HE}$ must also remain low or unlikely.

\section{A.5 UNIFORM CORROSION}

Lini (1975) reviewed the corrosion studies carried out at Hanford and concluded that "general corrosion is the least serious threat to tank integrity."

Divine et al. (1985) studied the uniform corrosion, localized corrosion, and SCC of A-516 and A-537 carbon steels over a wide range of Hanford waste compositions and temperatures. The composition ranges were as follows:

Hydroxide, 0.001 to $10 \mathrm{M}$

Nitrate, 0.05 to $4.7 \mathrm{M}$

Nitrite, .01 to $2.0 \mathrm{M}$ 
Organic complexants

Phosphate, sulfate, alumina were present

Chloride was not present

Temperatures ranged from 25 to $180^{\circ} \mathrm{C}$ in tests covering 4 to 12 months. A statistical test design was implemented to choose the solution compositions for the test solutions. At the end of the tests, uniform corrosion rates were parameterized using a polynomial data fit. Most of the corrosion data are in the form of large polynomials rather than graphs. "In general, corrosion rates were less than $1 \mathrm{mil}$ per year (mpy) $(0.001 \mathrm{inch} / \mathrm{yr})$ and usually less than $0.5 \mathrm{mpy}$. Excessive corrosion rates (greater than $1 \mathrm{mpy}$ ) were found only in dilute waste compositions or in concentrated caustic compositions at temperatures above $140{ }^{\circ} \mathrm{C}$." The test results indicated that uniform corrosion was not expected to be important in this environment. Due to the type of statistical analysis, it was not possible to judge the strength of a variable from the size of the coefficient in the polynomial. No crevice attack was observed.

Payer et al. (1975) studied SCC and uniform corrosion rates in a variety of synthetic salt cakes at 50 and $93^{\circ} \mathrm{C}$. In most cases, the uniform corrosion rates were less than 0.2 mpy. However, at $93^{\circ} \mathrm{C}$ in $5.75 \mathrm{M} \mathrm{NaOH}$ (no nitrate and nitrite), a corrosion rate as high as 16 mpy was determined. In one other case, 5.75 $\mathrm{M} \mathrm{NaOH}, 2.9 \mathrm{M} \mathrm{NaNO}_{3}$, and $1.53 \mathrm{M}$ $\mathrm{NaNO}_{2}$, a corrosion rate of 14 mpy was determined. Corrosion rates were lower at $50{ }^{\circ} \mathrm{C}$. Danielson and Bunnell (1994) carried out a statistically designed waste composition study of the behavior of carbon steel in the dilute waste environment to support sludge washing activities. The maximum corrosion rate on coupons exposed to the vapor, vapor/solution, and solution phase was 0.15 mpy indicating that uniform corrosion will not be a problem. Shallow knifeline (1.5 mils deep) attack was observed in solution \#1 (0.025 M nitrite, $0.393 \mathrm{M}$ nitrate, $0.026 \mathrm{M}$ hydroxide), but this is a composition regime that must be avoided because it results in SCC and crevice corrosion.

\section{A.6 MICROBIOLOGICALLY INFLUENCED CORROSION (MIC)}

Microbiologically influenced corrosion (Kobrin 1993) is the most difficult type of corrosion to prove because microorganisms are ubiquitous, and the damage is similar to non-MIC corrosion damage. Microbiologically influenced corrosion is characterized by colonies of bacteria and fungi that attach to a metallic surface. Their locally-produced metabolic products act as anodic depolarizers and/or cathodic depolarizers to produce pitting or crevice corrosion attack. One of the most infamous bacterium is the anaerobic sulfate-reducing bacterium that reduces sulfate to sulfide. The sulfide is particularly damaging to carbon steels, and the sulfate-reducing bacterium damage is characterized by paths of irregular pits containing a black sulfide deposit. However, there are many other types of bacteria, and often they co-exist in colonies. For instance, there are sulfur/sulfide-oxidizing bacteria, acid producing, iron-oxidizing, and acetate-oxidizing bacteria. The optimum temperature range for most of these bacteria is 20 to $50{ }^{\circ} \mathrm{C}$, but there are examples of bacteria that live above $100^{\circ} \mathrm{C}$ and presumably at high ionizing radiation dose rates. Because the clues are often the 
presence of sulfur, phosphate, and irregular regions of attack, identification of MIC is difficult. In the case of carbon steel, sulfur and phosphorus are always present as tramp elements, making this.characteristic difficult to interpret. Tubercles on carbon steel are also strong indicators of MIC. A key observation for differentiating the mechanisms is that increasing the temperature decreases the corrosion kinetics associated with MIC while at the same time that increasing the corrosion rate from non-MIC causes. The presence of microorganisms in the solution is not indicative of a MIC problem since they are always present. It is the attached, but usually out of sight, colonies that are the most dangerous. Definitive identification of MIC is usually accomplished by duplicating the process in the laboratory. Control of MIC is usually accomplished by cleaning the system followed by the use of biocides such as ozone, chlorine, hydrogen peroxide or surfactants.

The effect of ionizing radiation upon MIC is largely unknown, and it is often assumed that radiation fields that are dangerous to human life would also strongly inhibit or stop microbial growth. However, there is a famous case (Katonak and Hofstetter 1987) of a microbiological bloom (which seriously obscured the water clarity and hampered the cleanup) in the melted core of the Three Mile Reactor, Unit 2. Hydraulic fluid was accidentally leaked into the cooling and shielding water when a hydraulic hose burst, and the microbes used the oil as a nutrient. The radiation levels (TMI 1979) in the recirculating water were determined to be approximately $200 \mu \mathrm{Ci} / \mathrm{ml}$ gross activity (predominantly Cs-137). Although radiation levels adjacent to the broken core elements must have been extremely high, no reference can be found supporting the existence of such high radiation levels. The microbes were not identified because most of the effort was devoted to determining the optimal biocide (hydrogen peroxide proved most efficacious) and filter techniques. Microbiologically influenced corrosion was not observed during the period of active microbe growth. Clearly, microbiological growth is possible under ionizing radiation conditions, but the propensity for MIC is completely unexplored.

Danielson and Bunnell (1994) carried out a statistically designed waste composition study of the corrosion behavior of carbon steel in the dilute waste environment to support sludge washing activities. Coupons with evidence of pitting and crevice corrosion were submitted to scanning electron microscopy to evaluate whether certain metabolic products characteristic of microbial life were present (i.e., sulfur and phosphorus). Only one case of localized attack occurred in which MIC might have been involved.

\section{REFERENCES}

Awad, G. H., and T. P. Hoar, 1975, "The Role of Phosphates in Inhibiting Pitting of Commercial Mild Steel in Chloride-Containing Media." Corrosion Science, Vol. 15, pp. 581-588. 
Beavers, J. A., N. G. Thompson, R. N. Parkins, 1985, "Stress-Corrosion Cracking of Low Strength Carbon Steels in Candidate High Level Waste Repository Environments: Environmental Effects." Nuclear and Chemical Waste Management, Vol. 5, pp. 279-296.

Beck, W. J, J. O'M. Bockris, J. McBreen and L. Nanis, 1966, Proceedings of the Royal Society, London, A 2909, 220.

Bernstein, I. M., R. Garber and G. M. Pressouyre, 1976, "Effect of Dissolved Hydrogen on Mechanical behavior of Metals," in Effect of Hydrogen on Behavior of Materials. Proceedings of an International Conference, Moran, Wyoming.

Bickford, D. F., J. W. Congdon, and S. B. Oblath, 1986, "Electrochemical Probing of High-Level Radioactive Waste Tanks Containing Washed Sludge and Precipitates," DP-MS-86-178, E. I. DuPont de Nemours and Company, Savannah River Site, Aiken, South Carolina.

Bieber, G. J., June 1982, "The Stepwise Cracking of Line-Pipe Steels in Sour Environments," Materials Performance.

Bockris, J. O'M, J. McBreen, and L. Nanis, 1965, Journal of the Electrochemical Society, Vol 112, No. 10.

Bockris, J. O’M, B. E. Conway, E. Yeager, and R. E. White, 1981, "Comprehensive Treatise of Electrochemistry," Vol. 4, p. 423, Plenum Books, New York.

Claiborne, H. C., A. G. Croff, J. C. Griess, and F. J. Smith, 1985, Repository Environmental Parameters Relevant to Assessing the Performance of High-Level Waste Packages, NUREG/CR-4134.

Cotterill, P., "The Hydrogen Embrittlement of Metals", 1961, Vol. 9. in Progress in Materials Science, Pergamon Press, New York, New York.

Danielson, M. J. and L. R. Bunnell, 1994, "Sludge Washing Materials Study: The Behavior of Carbon Steel in a Dilute Waste Environment," TWRS PP-94-025, Pacific Northwest Laboratory, Richland, Washington.

Divine, J. R., W. M. Bowen, D. R. Mackey, D. J. Bates, and K. H. Pool, 1985, "Prediction Equations for Corrosion Rates of A-537 and A-516 Steels in Double Shell Slurry, Future Purex, and Hanford Facilities Wastes," PNL-5488, Pacific Northwest Laboratory, Richland, Washington.

Donovan, J. A., 1977, "Factors Controlling Nitrate-Cracking of Mild Steel," Corrosion 77, San Francisco, Califomia. 
Elmore, M. R., 1993, "Interim Report: Corrosion Evaluation of Tank 8D-2 Under Simulated 3rd-State Sludge Wash Conditions," Prepared for West Valley Nuclear Services, West Valley, New York.

Fessler, R. R., 1976, "Combination of Conditions Causing Stress Corrosion Cracking." Oil Gas, Vol. 74, p. 81.

Hirth, J. P., 1980, "Effects of Hydrogen on the Properties of Iron and Steel," Metallurgical Transactions, American Society for Metals and the Metallurgical Society of AIME, Vol 11a.

Kaesche, H., 1985, Metallic Corrosion, NACE, Houston, Texas.

Katonak, L. E., and K. J. Hofstetter, 1987, "Microorganisms, Filters, and Water Clarity of TMI-2," Proceedings of the Symposium on Waste Management at Tucson, Arizona.

Kirch, N. W., 1984, "Technical Basis for Waste Tank Corrosion Specifications," SD-WM-TI-150, Rockwell Hanford Operations, Richland, Washington.

Kobrin, G., 1993, Microbiologically Influenced Corrosion, NACE, Houston, Texas.

Lini, D. C., 1975, "Compilation of Hanford Corrosion Studies," ARH-ST-111, Atlantic Richfield Hanford Company, Richland, Washington.

Lynch, S. P., 1984, "A Fractographic Study of Gaseous Hydrogen Embrittlement and Liquid-Metal Embrittlement in a Tempered-Martensitic Steel, " Acta Metallurgica, Vol 32, No. 1, pp 79-90.

Matsuda, S., and H. H. Uhlig, 1964, "Effect of pH, Sulfates, and Chlorides on Behavior of Sodium Chromate and Nitrite as Passivators for Steel," Journal of the Electrochemical Society, Vol. 111, pp. 156-161.

Mahidhara, R. K., T.S. Elleman, and K. L. Murty, 1992, "Corrosion Failure Processes in Low Carbon Steels," North Carolina State University, Raleigh, NC, for Los Alamos National Laboratory, Contract No. 9-XQ-Y3122-1, p. 43.

McCright, R. D., 1977, "Effects of Environmental Species and Metallurgical Structure on the Hydrogen Entry into Steel, "in Stress Corrosion Cracking and Hydrogen Embrittlement of Iron Base Alloys, NACE-5, 1977 (Conf. in 1973), Houston, Texas.

Metals Handbook, Ninth Edition, 1987, Vol. 13, Corrosion, American Society for Metals, Metals Park, Ohio.

Nelson, H. G., 1983, "Hydrogen Embrittlement," in Treatise on Materials Science and Technology. Vol 25, Academic Press. 
Ondrejcin, R. S., 1977, "Investigation of Cooling Coil Corrosion in Radioactive-Waste Storage Tanks," Report \#DP-1425, E. I. DuPont de Nemours and Company, Savannah River Site, Aiken, South Carolina.

Ondrejcin, R. S., S. P. Rideout, and J. A. Donovan, 1979, "Control of Stress Corrosion Cracking in Storage Tanks Containing Radioactive Waste," Nuclear Technology, Vol. 44, pp. 297-306.

Ondrejcin, R. S., 1984, "Prevention of Stress Corrosion Cracking in Nuclear Waste Storage Tanks, Paper \#258, Corrosion 84, April 2-6, 1984 held at New Orleans.

Payer, J. H., R. B. Diegle, and W. K. Boyd, 1975, Corrosivity of Synthetic Salt Cake, ARC-C-22, Battelle Columbus Laboratories, Columbus, Ohio.

Schwenk, E. B., and J. R. Divine, 1993, "Proposed Corrosion Assessment of Hanford Waste Storage Tanks in Support of Interim Safety Basis Report," EBS-93-009, Westinghouse Hanford Company, Richland, Washington.

Smialowski, M., 1972, "Effect of Electrolytic Charging Conditions on Hydrogen Penetration and Embrittlement of Various Steels," Congres International, L'Hydrogene Dans Les Metaux, Editions Science, Paris, 1972, pp. 300-305.

Smialowska, Z., 1986, Pitting Corrosion of Metals, NACE, Houston, Texas.

Stoloff, N. S., 1984, "Metal Induced Embrittlement - A Historical Perspective," in Embrittlement by Liquid and Solid Metals, Ed. M. H. Kamdar, 1984, The Metallurgical Society of the American Institute of Mining, Metallurgical, and Petroleum Engineers, New York, New York.

Strehblow, H.H., and B. Titze, 1977, "Pitting Potentials and Inhibition Potentials of Iron and Nickel for Different Aggressive and Inhibiting Anions," Corrosion Science, Vol. 17, pp. 461-472.

Tetelman, A. S., and S. Kunz, 1977, "A Unified Model for Hydrogen Embrittlement, Liquid Metal Embrittlement, and Temper Embrittlement Due to Weakening of Atomic Bonds," in Stress Corrosion Cracking and Hydrogen Embrittlement of Iron Base Alloys, NACE-5,1977 (Conf. in 1973), National Association of Corrosion Engineers, Houston, Texas.

TMI Nuclear Power Plant Accident Hearings Before the Subcommittee on Environment and Public Works, Part 3, Cleanup and Recovery, November 8 and 9, 1979, 96th Congress, 1st Session. 
Tuttle, R. N., and J. W. Kochera, 1975, "Control of Hydrogen Embrittlement in Deep Gas Wells," in Effect of Hydrogen on Behavior of Materials. Proceedings of an International Conference, Moran, Wyoming.

Venu, K., K. Balakrishnan, and K. S. Rajagopalan, "Potentiokinetic Polarization Study of the Behavior of Steel in NaOH-NaCl System," Corrosion Science, Vol. 5, pp. 59-69.

Warren, D., 1986, "Hydrogen Effects on Steel, " Process Industries Corrosion, NACE, p. $31-43$.

Zapp, P. E., and D. T. Hobbs, 1992, "Inhibiting Pitting Corrosion in Carbon Steel Exposed to Dilute Radioactive Waste Slurries, " NACE Corrosion 92, Paper \#98.

\section{REFERENCES FOR TABLE A-1}

1. Parks, D. H., 1957, Examination of Corrosion Test Coupons in PUREX 101 Waste Storage Tanks - RM-147, HW-49574, General Electric Co., Richland, Washington.

2. Endow, N. and K. L. Sanborn, 1954, Field Corrosion Test SAE 1020 Carbon Steel in Redox Process Waste Solution Tank No. 104, 241-S, HW-32755, General Electric Company, Richland, Washington.

3. Sanborn, K. L., 1949, A Survey of Corrosion Data and Construction Details, 200 Area Waste Storage Tanks, HW-14946, General Electric Co., Richland, Washington.

4. Endow, N., 1954, A Laboratory Study of the Extent of Pitting and General Corrosion of SAE-1010 Steel in Simulated Neutralized PUREX Process Waste Solution, HW-32734, General Electric Company, Richland, Washington.

5. Groves, N. D., 1953, Corrosion Effects of Lowering pH of the TBP Waste Stream, In: Technical Activities Report - Corrosion and Welding, HW-29183, General Electric Company, Richland, Washington.

6. Sanborn, K. L., 1952, A Study of the Effect of pH of First Cycle Bismuth Phosphate Waste on the Corrosion of Mild Steel, HW-26202, General Electric Company, Richland, Washington.

7. Lini, D. C., 1975, Compilation of Hanford Corrosion Studies, ARH-ST-111, Atlantic Richfield Hanford Company, Richland, Washington.

8. Payer, J. H., R. B. Diegle, and W. K. Boyd, 1975, Corrosivity of Synthetic Salt Cake, ARC-C-22, Battelle Columbus Laboratories, Columbus, Ohio. 
9. Endow, N., 1954, Field Corrosion Tests - SAE 1020 Steel in Bismuth Phosphate Process Waste Solution Tanks, HW-30641, General Electric Company, Richland, Washington.

10. Pitzer, E. C., 1952, Corrosion Tests - SAE 1010 Mild Steel in Synthetic Metal Waste Solution, HW-24136, General Electric Company, Richland, Washington.

11. Endow, N., 1952, Corrosion Tests - SAE 1010 Mild Steel in Synthetic Neutralized REDOX Waste Solution, HW-26201, General Electric Company, Richland, Washington.

12. Stallwood, T. E., 1957, Examination of Field Corrosion Test Coupons from Hot Semi-Works, HW-49574, General Electric Company, Richland, Washington.

13. Ward, R., 1953, Technical Activities Report Metallurgy-Applied Research Unit, HW-27097, General Electric Company, Richland, Washington. 


\section{DISTRIBUTION}

\section{Number of Copies}

\section{OFFSITE}

2

U.S. Department of Energy

EM-362, 312 Trevion Bldg.

Germantown, MD 20874
A. Griffith
C. S. O'Dell

3

Westinghouse Savannah River Company

P. O. Box 616

Aiken, SC 29802

N. C. Iyer

J. E. Marra

R. L. Sindelar

5

U.S. Department of Energy

Richland Operations Office

G. E. Bishop

R3-72

C. O. Ruud

S7-54

A. B. Sidpara

R3-72

Public Reading Room (2)

Pacific Northwest Laboratory

M. J. Danielson

P8-44

J. W. Johnston

K7-34

K. E. Noffsinger

K5-20

P. A. Scott

P7-43

R. E. Westerman

P8-44

Kaiser Engineers Hanford Company

C. H. Brevick

G7-56

L. J. Garvin

G7-56

E. A. Vickery

G7-56 
DISTRIBUTION (continued)

\section{Number of Copies}

\section{ONSITE}

Westinghouse Hanford Company

R. P. Anantatmula (12) R1-30

N. G. Awadalla

R $1-30$

G. D. Bazinet

S4-53

L. D. Blackburn

H5-67

V. C. Boyles

R1 -49

W. F. Brehm

H5-67

W. C. Carlos

H5-67

C. W. Dunbar

R1-30

D. B. Engelman

R1-49

J. H. Haberman

R1-30

J. M. Henderson

S6- 12

G. A. Meyer

S4-54

W. C. Miller

S4-55

J. L. Nelson

R1-30

P. C. Ohl

R $1-30$

M. A. Payne

S7-14

J. G. Propson

S4-58

T. E. Rainey

R4-02

R. E. Raymond

R2-54

E. B. Schwenk

H5-52

K. V. Scott

H5-52

E. J. Shen

S4-58

K. G. Squires

S6-12

R. R. Stickney

R4-02

J. D. Thomson

R1-30

G. R. Wilson

S7-14

Central Files (2)

L8-04

EDMC

H6-08

Information Release Administration (3)

R1-05

TFIC

R1-20 

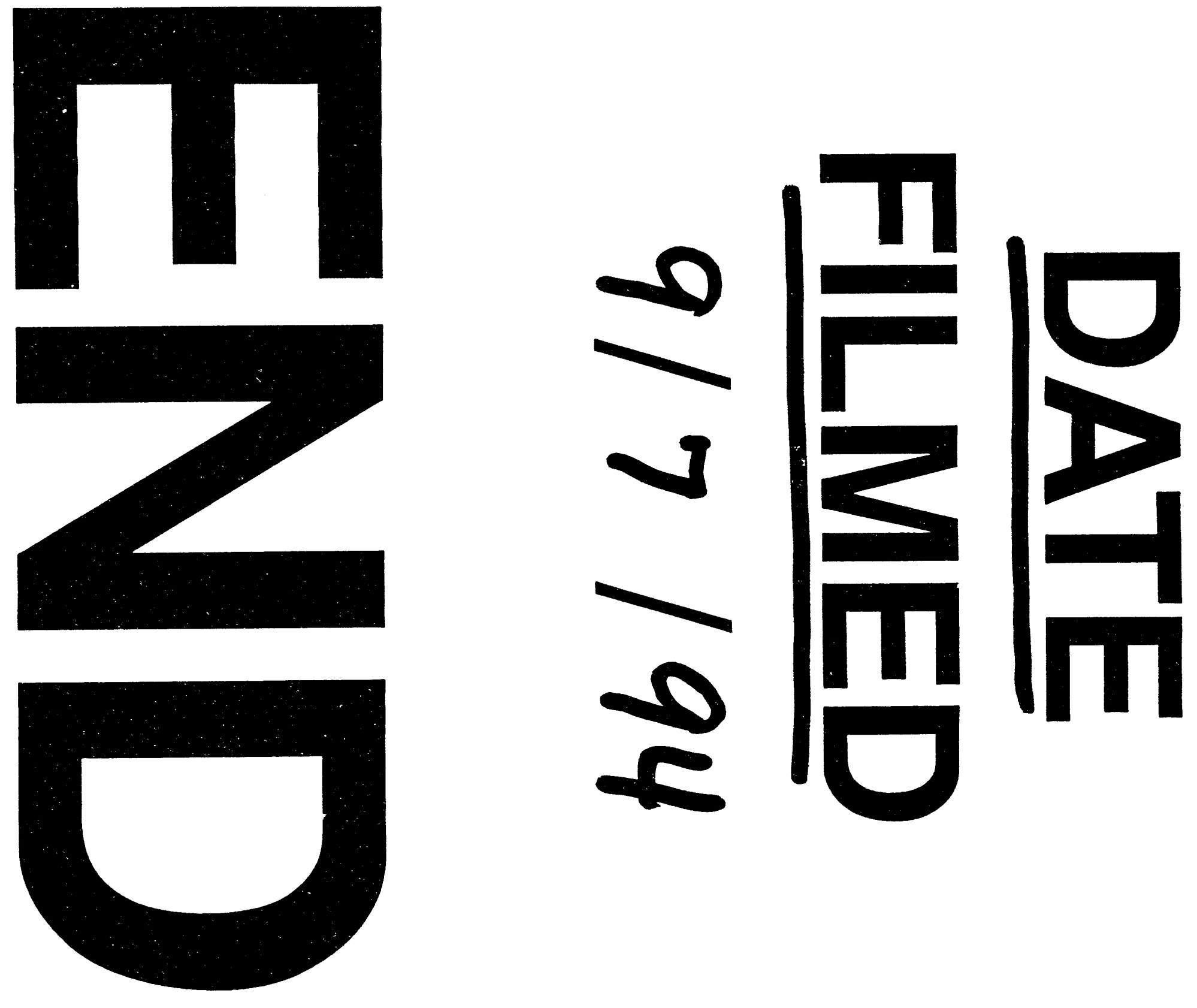


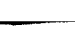

